Federal Reserve Bank of Dallas

Globalization and Monetary Policy Institute

Working Paper No. 86

http://www.dallasfed.org/assets/documents/institute/wpapers/2011/0086.pdf

\title{
Do Banking Shocks Matter for the U.S. Economy?*
}

\author{
Naohisa Hirakata \\ Bank of Japan \\ Nao Sudo \\ Bank of Japan \\ Kozo Ueda \\ Bank of Japan
}

July 2011

\begin{abstract}
The quantitative significance of shocks to the financial intermediary (FI) has not received much attention up to now. We estimate a DSGE model with what we describe as chained credit contracts, using Bayesian technique. In the model, credit-constrained FIs intermediate funds from investors to credit-constrained entrepreneurs through two types of credit contract. We find that the shocks to the FIs. net worth play an important role in the investment dynamics, accounting for $17 \%$ of its variations. In particular, in the Great Recession, they are the key determinants of the investment declines, accounting for $36 \%$ of the variations.
\end{abstract}

JEL codes: E31, E44, E52

\footnotetext{
* Naohisa Hirakata, Deputy Director, Research and Statistics Department, Bank of Japan, 2-1-1 Nihonbashi, Hongoku-cho, Chuo-ku, Tokyo 103, Japan. Naohisa.hirakata@boj.or.jp. Nao Sudo, Associate Director, Institute for Monetary and Economic Studies, Bank of Japan, 2-1-1 Nihonbashi, Hongoku-cho, Chuo-ku, Tokyo 103, Japan. Nao.sudou@boj.or.jp. Kozo Ueda, Director, Institute for Monetary and Economic Studies, Bank of Japan, 2-1-1 Nihonbashi, Hongoku-cho, Chuo-ku, Tokyo 103, Japan. 81 (0) 33277-1163. Kouzou.ueda@boj.or.jp. The authors would like to thank Michel Juillard, two anonymous referees, Klaus Adam, Hiroshi Osano, Mathias Trabandt, Karl Walentin, Toshiaki Watanabe, Wako Watanabe, seminar participants at Kyoto University, the Bank of Canada, the Bank of Italy, the JEDC Conference on Frontiers in Structural Macroeconomic Modeling, and the staff of the Institute for Monetary and Economic Studies (IMES) and the Bank of Japan for their useful comments. The authors particularly thank Simon Gilchrist and Lawrence Christiano for their encouragement at the outset of this research. The views in this paper are those of the authors and do not necessarily reflect the views of the Bank of Japan, the Federal Reserve Bank of Dallas or the Federal Reserve System.
} 


\section{Introduction}

The financial crisis that began in the fall of 2007 demonstrated that financial intermediaries (hereafter, FIs) play a crucial role in economic activity. Adverse shocks to the FI sector increase the borrowing costs for the FIs by deteriorating their net worth. Consequently, the supply of funds to entrepreneurs tightens, leading to an investment decline and a further deterioration in the FIs' net worth. This account is consistent with the literature that focuses on the relationship between the FI sector and the aggregate economy. For example, Peek and Rosengren (1997, 2000), using a novel identification scheme for a loan supply shock, report that the worsening of the FIs' net worth generates economic downturns.

However, there is as yet no body of literature determining how important the shocks to the FI sector are to the U.S. business cycle. While macroeconomists agree that shocks to the credit market are an important source of aggregate fluctuations, to the best of our knowledge only a limited number of studies have evaluated the relative impact of shocks to the FI sector. ${ }^{1}$ In the existing models, shocks to the entrepreneurial net worth are primarily focus and shocks to the FIs' net worth are often neglected.

To assess the role of the shocks to the FIs' net worth, we estimate the financial accelerator model of Hirakata, Sudo, and Ueda (2009, 2011, hereafter HSU). Our model is built upon the financial accelerator model in Bernanke, Gertler, and Gilchrist (1999, hereafter BGG) where endogenous developments in the entrepreneurial net worth play an important role in amplifying and propagating exogenous shocks. In our model, FIs intermediate funds from investors to entrepreneurs through two types of credit contract. Because the FIs as well as the entrepreneurs are credit constrained, the financial accelerator effect is enhanced due to developments in the FIs' net worth along with the entrepreneurial net worth.

Based on HSU (2009, 2011), we distill the shocks to the FIs' net worth using a Bayesian technique. We employ a set of U.S. macroeconomic variables consisting of output, consumption, investment, inflation, the policy rate, and the net worth of the FI and entrepreneurial sectors. ${ }^{2}$ The sample period runs from 1984Q1 to 2010Q4, and therefore covers the most recent turmoil in the credit market. We find that the estimated adverse shocks to the FIs' net worth typically take large negative values during the recession, and are correlated with an indicator of credit market stress.

A negative shock to the FIs' net worth causes a persistent decline in investment. In particular, during the several quarters since 2007, the shocks to the FIs' net worth were

\footnotetext{
${ }^{1}$ See, for example, Gilchrist, Yankov, and Zakrajsek (2009) and Jermann and Quardini (2009). The notable exceptions are Christiano, Motto, and Rostagno (2008, 2009, hereafter CMR), who analyze the shocks to the production technology of the banks separately from the shocks to the entrepreneurs. While other empirical work, such as Peek and Rosengren (1997, 2000), emphasizes the balance-sheet effect in the FI sector, the banks in CMR $(2008,2009)$ are competitive and do not own their net worth. In contrast, we focus on the shocks to the FIs' net worth and their impact on the aggregate economy.

${ }^{2}$ As discussed below, we conduct several sensitivity analyses of the choice of observable variables.
} 
unprecedentedly deep and persistent, contributing to a drastic widening in the borrowing spreads in that period. Their impacts on investment lasted a long time, lowering it for several quarters after the end of the recession.

Quantitatively, the shocks to the FIs net worth are an important source of the investment dynamics, accounting for $17 \%$ of the investment variations throughout our sample period. In particular, they are the main source of the investment slump during the Great Recession, accounting for $36 \%$ of the investment variations during the period.

Since the shocks to the entrepreneurial net worth also drive a substantial portion of the investment variations, the sum of the two net worth shocks explains $55 \%$ and $64 \%$ of the investment variations over the entire sample period and the period of the Great Recession, respectively. These net worth shocks are amplified to the macroeconomy thanks to the credit market imperfection, reinforcing each other through the endogenous developments in the two net worths. This transmission mechanism is particularly consistent with the key features of the Great Recession, including the financial market turmoil and the collapse of the major financial institutions associated with the deterioration in the FIs' net worth.

The influence of the shocks to the FIs' net worth on output and inflation are minor, accounting for only $4 \%$ of their variations over the entire sample period. Even during the Great Recession, the shocks account for $7 \%$ of output variations and $9 \%$ of inflation variations. By contrast, the non-financial shocks, in particular, the preference shocks and the technology shocks, play the dominant role in explaining these variables.

Research using the financial accelerator model commonly poses one or both of two questions. ${ }^{3}$ The first concerns the quantitative importance of the financial shocks that originate in the credit market, and the second concerns the quantitative importance of the financial accelerator effect. For instance, in response to the first question, Nolan and Thoenissen (2009) report that shocks to the credit market account for $45 \%$ of the investment variations. In response to the second question, Christensen and Dib (2008) conclude that the financial accelerator mechanism brings the sticky-price dynamic stochastic general equilibrium (DSGE) model closer to the data although they stress that its quantitative contribution is small. ${ }^{4}$

By adding to the model credit-constrained FIs and shocks to their net worth, we provide more extensive answers to the two questions. First, consistent with the existing literature, our result implies that financial shocks originating in the credit market substantially affect the macroeconomy. Moreover, a sizable amount of the estimated shocks to the credit market originates in the FI sector as well as in the entrepreneurial sector. Second, in comparing fit with the data, we find that our model, in which both the FIs and the entrepreneurs are credit constrained, outperforms the model in which only the

\footnotetext{
${ }^{3}$ See, for example, CMR (2008), Meier and Muller (2006), Christensen and Dib (2008), De Graeve (2008), and Nolan and Thoenissen (2009).

${ }^{4}$ Meier and Muller (2006) derive a similar conclusion that the financial accelerator effect is small by investigating impulse response functions to monetary policy shocks using U.S. data.
} 
entrepreneurs are credit constrained. Our comparison suggests that the financial accelerator mechanism linked to endogenous developments in the FIs' net worth is an important element in explaining the data.

The remainder of the paper is organized as follows. In Section 2, we describe our economy. In Section 3, we describe the estimation method and the results. Section 4 concludes.

\section{The Economy}

We consider an economy with a credit market and a goods market. The economy consists of 10 types of agents: investors, FIs, entrepreneurs, a household, final goods producers, retailers, wholesalers, capital goods producers, the government, and the monetary authority.

The setting for the credit market is taken from HSU (2009). There are three types of participants in the credit market: investors, FIs, and entrepreneurs. Investors collect deposits from the household in a competitive market, and invest what they collect in loans to the FIs. FIs are the monopolistic lenders of funds to entrepreneurs. The FIs own their net worth, but not sufficiently to finance their loans to the entrepreneurs. Therefore, they make credit contracts with the investors to borrow the rest of the funds. Entrepreneurs invest in their projects, and also own their net worth, but not sufficiently to finance them. Thus, they make credit contracts with the FIs to borrow the funds. Clearly, these two types of contracts are linked in the economy, and the entrepreneurs cannot finance their projects if either of the credit contracts fails to hold.

In the model, the monopolistic FIs determine the borrowing rates of the two credit contracts, thereby ensuring the participation constraints of entrepreneurs and investors. Agency problems arise from the asymmetric information between lenders and borrowers for both of the credit contracts, one between the FIs and the entrepreneurs (hereafter, FE contracts) and the other between the investors and the FIs (hereafter, IF contracts). ${ }^{5}$ Consequently, the borrowing rates of the credit contracts change with the net worth of the borrowers.

The assumption of the monopolistic FIs is essential to our model. In BGG (1999), the FIs face perfect competition, earning zero profit. By contrast, since our FIs are the monopolistic supplier of the loans to the entrepreneurs, they earn profits from the credit

\footnotetext{
${ }^{5}$ Our setting thus contrasts with other banking models based on the moral hazard problems of FIs and entrepreneurs (Chen, 2001; Meh and Moran, 2004; and Aikman and Paustian, 2006). These studies all develop quantitative extensions of the model in Holmstrom and Tirole (1997) and illustrate the role of the net worth in the banking sector. Importantly, in their models a rise in the FIs' net worth affects the aggregate investment through the moral hazard problem among the entrepreneurs, the firms, and the investors. By contrast, our model stresses the role of the FIs' net worth in affecting the economy through the borrowing rates of the credit contracts.
} 
contracts, accumulating their own net worth. ${ }^{6}$ This setting is in line with the existing studies such as Klein (1971), Monti (1972), and Freixas and Rochet (2008).

We closely follow BGG (1999) for the setup of the goods market. There are four goods in the economy: final goods, retail goods, wholesale goods, and capital goods. Final goods are produced by final goods producers from differentiated retail goods through the Dixit-Stiglitz aggregator. Retail goods are produced from wholesale goods by monopolistic retail goods producers that set the prices of their goods following Calvo (1983). Wholesale goods are produced by competitive wholesalers that own a Cobb-Douglas production technology which converts capital and labor inputs into wholesale goods. Capital goods are produced by capital goods producers and sold to the entrepreneurs. In what follows, we briefly describe our setting of the credit market and fully explain the goods market.

\subsection{The Credit Market}

\section{Overview of the two types of credit contract}

In this section, we describe the framework of the credit contracts. In each period, entrepreneurs conduct projects with size $Q\left(s^{t}\right) K\left(s^{t}\right)$, where $Q\left(s^{t}\right)$ is the price of capital and $K\left(s^{t}\right)$ is capital. Entrepreneurs own their net worth, $N^{E}\left(s^{t}\right)<Q\left(s^{t}\right) K\left(s^{t}\right)$, and borrow funds, $Q\left(s^{t}\right) K\left(s^{t}\right)-N^{E}\left(s^{t}\right)$, from the FIs through the FE contracts. The FIs also own their net worth, $N^{F}\left(s^{t}\right)<Q\left(s^{t}\right) K\left(s^{t}\right)-N^{E}\left(s^{t}\right)$, and borrow funds, $Q\left(s^{t}\right) K\left(s^{t}\right)-N^{F}\left(s^{t}\right)-N^{E}\left(s^{t}\right)$, from investors through the IF contracts. In both contracts, agency problems stemming from asymmetric information are present. That is, the borrowers are subject to idiosyncratic productivity shocks and the lenders cannot observe the realizations of these shocks without paying additional costs. ${ }^{7}$ Taking these credit market imperfections as given, the FIs choose the clauses of the two contracts that maximize their expected profits. Consequently, for a given riskless rate of the economy $R\left(s^{t}\right)$, the external finance premium $\mathrm{E}_{t}\left\{R^{E}\left(s^{t+1}\right)\right\} / R\left(s^{t}\right)$ is expressed by

\footnotetext{
${ }^{6}$ In the current model, the entrepreneurs are grouped and each of the groups is attached to a certain type of FI. They cannot raise funds from another type of FI. Consequently, the competition among the different types of the FIs in the loan market is absent from the model.

${ }^{7}$ The idiosyncratic productivity shocks for the FIs and the entrepreneurs are log-normally distributed with unit mean and standard deviations $\sigma_{F}$ and $\sigma_{E}$, respectively. In Subsection 3.5, we investigate the cases where stochastic process of these productivity shocks are time-variant.
} 


$$
\begin{aligned}
& \text { inverse of the share of profit going to the investors in the IF contract } \\
& \frac{\mathrm{E}_{t}\left\{R^{E}\left(s^{t+1}\right)\right\}}{R\left(s^{t}\right)}=\overbrace{\Phi^{F}\left(\bar{\omega}^{F}\left(\frac{N^{F}\left(s^{t}\right)}{Q\left(s^{t}\right) K\left(s^{t}\right)}, \frac{N^{E}\left(s^{t}\right)}{Q\left(s^{t}\right) K\left(s^{t}\right)}\right)\right)^{-1}} \\
& \times \overbrace{\Phi^{E}\left(\bar{\omega}^{E}\left(\frac{N^{E}\left(s^{t}\right)}{Q\left(s^{t}\right) K\left(s^{t}\right)}\right)\right)^{-1}} \\
& \text { ratio of the debt to the size of the capital investment } \\
& \times \overbrace{\left(1-\frac{N^{F}\left(s^{t}\right)}{Q\left(s^{t}\right) K\left(s^{t}\right)}-\frac{N^{E}\left(s^{t}\right)}{Q\left(s^{t}\right) K\left(s^{t}\right)}\right)} \\
& \equiv F\left(n^{F}\left(s^{t}\right), n^{E}\left(s^{t}\right)\right) \text {, }
\end{aligned}
$$

with

$$
\begin{aligned}
& \Phi^{F}\left(\bar{\omega}^{F}\left(s^{t+1} \mid s^{t}\right)\right) \equiv \overbrace{G^{F}\left(\bar{\omega}^{F}\left(s^{t+1} \mid s^{t}\right)\right)}^{\text {expected return from defaulting FIs }} \\
& \text { expected return from nondefaulting FIs } \\
& +\overbrace{\bar{\omega}^{F}\left(s^{t+1} \mid s^{t}\right) \int_{\bar{\omega}^{F}\left(s^{t+1} \mid s^{t}\right)}^{\infty} d F^{F}\left(\omega^{F}\right)} \\
& \text { expected monitoring cost paid by investors } \\
& -\overbrace{\mu^{F} G^{F}\left(\bar{\omega}^{F}\left(s^{t+1} \mid s^{t}\right)\right)} \\
& \text { expected return from defaulting entrepreneurs } \\
& \Phi^{E}\left(\bar{\omega}^{E}\left(s^{t+1} \mid s^{t}\right)\right) \equiv \overbrace{G^{E}\left(\bar{\omega}^{E}\left(s^{t+1} \mid s^{t}\right)\right)} \\
& \text { expected return from nondefaulting entrepreneurs } \\
& +\overbrace{\bar{\omega}^{E}\left(s^{t+1} \mid s^{t}\right) \int_{\bar{\omega}^{E}\left(s^{t+1} \mid s^{t}\right)}^{\infty} d F^{E}\left(\omega^{E}\right)} \\
& \text { expected monitoring cost paid by FIs } \\
& -\overbrace{\mu^{E} G^{E}\left(\bar{\omega}^{E}\left(s^{t+1} \mid s^{t}\right)\right)}
\end{aligned}
$$

where $n^{F}\left(s^{t}\right)$ and $n^{E}\left(s^{t}\right)$ are the ratios of net worth to aggregate capital in the two sectors, and $\bar{\omega}^{F}\left(s^{t+1} \mid s^{t}\right)$ and $\bar{\omega}^{E}\left(s^{t+1} \mid s^{t}\right)$ are the cutoff value for the FIs' idiosyncratic shock $\omega^{F}\left(s^{t+1}\right)$ in the IF contract and that for the entrepreneurial idiosyncratic shock 
$\omega^{E}\left(s^{t+1}\right)$ in the FE contract. ${ }^{89}$ Equation (1) is a key equation that links the net worth of the borrowing sectors to the external finance premium. The external finance premium is determined by three components: the share of profit in the IF contract going to the investors, the share of profit in the FE contract going to the FIs, and the ratio of total debt to aggregate capital. Lower profit shares going to the lenders cause a higher external finance premium through the first two terms of equation (1). Otherwise, the participation constraints of investors would not be met and financial intermediation fails. A higher ratio of the debt results in higher external costs, since it raises default probability of the IF contracts and investors require higher returns from the IF contracts to satisfy their participation constraint. The presence of the first two channels suggests that not only the sum of both net worths but also the distribution of the two net worths matter in determining the external finance premium.

\section{Borrowing rates}

The two credit borrowing rates, namely, the entrepreneurial borrowing rate and the FIs' borrowing rate, are given by the FE and the IF contracts, respectively. The entrepreneurial borrowing rate, denoted by $Z^{E}\left(s^{t+1} \mid s^{t}\right)$, is given as the contractual interest rate that nondefaulting entrepreneurs repay to the FIs:

$$
Z^{E}\left(s^{t+1} \mid s^{t}\right) \equiv \frac{\bar{\omega}^{E}\left(s^{t+1} \mid s^{t}\right) R^{E}\left(s^{t+1} \mid s^{t}\right) Q\left(s^{t}\right) K\left(s^{t}\right)}{Q\left(s^{t}\right) K\left(s^{t}\right)-N^{E}\left(s^{t}\right)} .
$$

Clearly, the numerator stands for the amount that the nondefaulting entrepreneurs repay to the FIs, and the denominator for the amount of funds that entrepreneurs borrow from the FIs.

Similarly, the FIs' borrowing rate, denoted by $Z^{F}\left(s^{t+1} \mid s^{t}\right)$, is given by the contractual interest rate that nondefaulting FIs repay to the investors. That is

$$
Z^{F}\left(s^{t+1} \mid s^{t}\right) \equiv \frac{\bar{\omega}^{F}\left(s^{t+1} \mid s^{t}\right) \Phi^{E}\left(\bar{\omega}^{E}\left(s^{t+1} \mid s^{t}\right)\right) R^{E}\left(s^{t+1} \mid s^{t}\right) Q\left(s^{t}\right) K\left(s^{t}\right)}{Q\left(s^{t}\right) K\left(s^{t}\right)-N^{F}\left(s^{t}\right)-N^{E}\left(s^{t}\right)},
$$

In equation (5), the numerator is the amount that the nondefaulting FIs repay to the investors, and the denominator is the amount of funds that the FIs borrow from the investors.

\section{Dynamic behavior of net worth}

The net worth of the FIs and the entrepreneurs, $N^{F}\left(s^{t}\right)$ and $N^{E}\left(s^{t}\right)$, depends on their earnings from the credit contracts and their labor income. In addition to the profits

\footnotetext{
${ }^{8}$ Similarly to BGG (1999) and CMR (2008), the aggregation problem of the FIs and the entrepreneurs becomes tractable thanks to the property of optimal credit contracts where the ratio of net worth to capital is the same within FIs and within entrepreneurs.

${ }^{9}$ See Appendix A for the details of credit contracts. See Appendix B for the explicit forms of $G^{F}\left(\bar{\omega}^{F}\left(s^{t+1} \mid s^{t}\right)\right)$ and $G^{E}\left(\bar{\omega}^{E}\left(s^{t+1} \mid s^{t}\right)\right)$.
} 
stemming from entrepreneurial projects, both FIs and entrepreneurs inelastically supply a unit of labor to final goods producers and receive labor income $W^{F}\left(s^{t}\right)$ and $W^{E}\left(s^{t}\right)$. As we assume that each FI and entrepreneur survives to the next period with a constant probability $\gamma^{F}$ and $\gamma^{E}$, then the aggregate net worths of the FIs and the entrepreneurs are given by

$$
\begin{aligned}
& N^{F}\left(s^{t+1}\right)=\gamma^{F} V^{F}\left(s^{t}\right)+W^{F}\left(s^{t}\right)+\varepsilon^{N^{F}}\left(s^{t}\right), \\
& N^{E}\left(s^{t+1}\right)=\gamma^{E} V^{E}\left(s^{t}\right)+W^{E}\left(s^{t}\right)+\varepsilon^{N^{E}}\left(s^{t}\right),
\end{aligned}
$$

with

$$
\begin{aligned}
V^{F}\left(s^{t}\right) & \equiv\left(1-\Gamma^{F}\left(\bar{\omega}^{F}\left(s^{t+1}\right)\right)\right) \Phi^{E}\left(\bar{\omega}^{E}\left(s^{t+1} \mid s^{t}\right)\right) R^{E}\left(s^{t+1}\right) Q\left(s^{t}\right) K\left(s^{t}\right), \\
V^{E}\left(s^{t}\right) & \equiv\left(1-\Gamma^{E}\left(\bar{\omega}^{E}\left(s^{t+1}\right)\right)\right) R^{E}\left(s^{t+1}\right) Q\left(s^{t}\right) K\left(s^{t}\right) .
\end{aligned}
$$

The FIs and the entrepreneurs that fail to survive at period $t$ consume $\left(1-\gamma^{F}\right) V^{F}\left(s^{t}\right)$ and $\left(1-\gamma^{E}\right) V^{E}\left(s^{t}\right)$, respectively. ${ }^{10}$

The net worth accumulations are affected by the exogenous shocks represented by $\varepsilon^{N^{F}}\left(s^{t}\right)$ and $\varepsilon^{N^{E}}\left(s^{t}\right)$ that are orthogonal to the fundamental earnings described above. We assume they are i.i.d. shocks. These two shocks capture financial shocks that reflect an "asset bubble," "irrational exuberance," or an "innovation in the efficiency of credit contracts," hitting the FI sector or the entrepreneurial sector. An adverse financial shock causes a malfunctioning of the credit market by reducing borrowers' net worth. Because the subsequent credit contracts charge higher borrowing rates to the borrowers, the external finance premium becomes more costly than otherwise, leading to a decline in aggregate investment. ${ }^{11}$

\subsection{The Rest of the Economy}

\section{Household}

A representative household is infinitely lived, and maximizes the following utility function:

$$
\max _{C\left(s^{t}\right), H\left(s^{t}\right), D\left(s^{t}\right)} \mathrm{E}_{t} \sum_{l=0}^{\infty} \exp \left(e^{B}\left(s^{t+l}\right)\right) \beta^{t+l}\left\{\log C\left(s^{t+l}\right)-\chi \frac{H\left(s^{t+l}\right)^{1+\frac{1}{\eta}}}{1+\frac{1}{\eta}}\right\},
$$

\footnotetext{
${ }^{10}$ See Appendix B for the definition of $\Gamma^{F}\left(\bar{\omega}^{F}\left(s^{t+1}\right)\right)$ and $\Gamma^{E}\left(\bar{\omega}^{E}\left(s^{t+1}\right)\right)$.

${ }^{11}$ The setting of these net worth shocks is borrowed from Gilchrist and Leahy (2002). See also CMR (2008) and Nolan and Thoenissen (2009) for an interpretation of these net worth shocks under credit market imperfection. In these studies, the exit ratio of entrepreneurs $\gamma^{E}$ obeys the stochastic law of motion, generating an unexpected change in the entrepreneurial net worth.
} 
subject to

$$
C\left(s^{t}\right)+D\left(s^{t}\right) \leq W\left(s^{t}\right) H\left(s^{t}\right)+R\left(s^{t}\right) D\left(s^{t-1}\right)+\Pi\left(s^{t}\right)-T\left(s^{t}\right),
$$

where $C\left(s^{t}\right)$ is final goods consumption, $H\left(s^{t}\right)$ is hours worked, $D\left(s^{t}\right)$ is real deposits held by the investors, $W\left(s^{t}\right)$ is the real wage measured by the final goods, $R\left(s^{t}\right)$ is the real risk-free return from the deposit $D\left(s^{t}\right)$ between time $t$ and $t+1, \Pi\left(s^{t}\right)$ is dividend received from the ownership of retailers, and $T\left(s^{t}\right)$ is a lump-sum transfer. ${ }^{12} \beta \in(0,1)$, $\eta$, and $\chi$ are the subjective discount factor, the elasticity of hours worked, and the utility weight on hours worked, respectively. $e^{B}\left(s^{t}\right)$ is a preference shock with mean one that provides the stochastic variation in the discount factor.

\section{Final goods producer}

The final goods $Y\left(s^{t}\right)$ are composites of a continuum of retail goods $Y\left(h, s^{t}\right)$. The final goods producer purchases retail goods in the competitive market, and sells the final goods to a household and capital producers at price $P\left(s^{t}\right) . P\left(s^{t}\right)$ is the aggregate price of the final goods. The production technology of the final goods is given by

$$
Y\left(s^{t}\right)=\left[\int_{0}^{1} Y\left(h, s^{t}\right)^{\frac{\epsilon-1}{\epsilon}} d h\right]^{\frac{\epsilon}{\epsilon-1}},
$$

where $\epsilon>1$. The corresponding price index is given by

$$
P\left(s^{t}\right)=\left[\int_{0}^{1} P\left(h, s^{t}\right)^{1-\epsilon} d h\right]^{\frac{1}{1-\epsilon}} .
$$

\section{Retailers}

The retailers $h \in[0,1]$ are populated over a unit interval, each producing differentiated retail goods $Y\left(h, s^{t}\right)$, with production technology:

$$
Y\left(h, s^{t}\right)=y\left(h, s^{t}\right),
$$

where $y\left(h, s^{t}\right)$ for $h \in[0,1]$ are the wholesale goods used for producing the retail goods $Y\left(h, s^{t}\right)$ by retailer $h \in[0,1]$. The retailers are price takers in the input market and choose their inputs taking the input price $1 / X\left(s^{t}\right)$ as given. However, they are monopolistic suppliers in their output market, and set their prices to maximize profits. Consequently, the retailer $h$ faces a downward-sloping demand curve:

$$
Y\left(h, s^{t}\right)=\left(\frac{P\left(h, s^{t}\right)}{P\left(s^{t}\right)}\right)^{-\epsilon} Y\left(s^{t}\right) .
$$

\footnotetext{
${ }^{12}$ Here, the households are implicitly insured for their deposits. As the budget constraint equation shows, they always receive the risk-free interest rate $R\left(s^{t}\right)$.
} 
Retailers are subject to nominal rigidity. They can change prices in a given period only with probability $\left(1-\xi_{p}\right)$, following Calvo (1983). Retailers who cannot reoptimize their price in period $t$, say $h=\bar{h}$, set their prices according to

$$
P\left(\bar{h}, s^{t}\right)=\left[\pi\left(s^{t-1}\right)^{\gamma_{p}} \pi^{1-\gamma_{p}}\right] P\left(\bar{h}, s^{t-1}\right),
$$

where $\pi\left(s^{t-1}\right)$ denotes the gross rate of inflation in period $t-1$, that is, $\pi\left(s^{t-1}\right)=$ $P\left(s^{t-1}\right) / P\left(s^{t-2}\right) . \pi$ denotes a steady state inflation rate, and $\gamma_{p} \in[0,1]$ is a parameter that governs the size of price indexation. Denoting the price set by the active retailers by $P^{*}\left(h, s^{t}\right)$ and the demand curve the active retailer faces in period $t+l$ by $Y^{*}\left(h, s^{t+l}\right)$, retailer $h$ 's optimization problem with respect to its product price $P^{*}\left(h, s^{t}\right)$ is written in the following way:

$$
\begin{aligned}
\sum_{l=0}^{\infty} \xi E_{t} \Lambda\left(s^{t+l}\right)\left(\pi^{\left(1-\gamma_{p}\right) l}(\right. & \left.\prod_{k=0}^{l-1} \pi^{\gamma_{p}}\left(s^{t+k}\right)\right) P^{*}\left(h, s^{t}\right) Y\left(h, s^{t+l}\right) \\
& \left.-\left(\frac{P\left(s^{t+l}\right)}{X\left(s^{t+l}\right)}\right) Y\left(h, s^{t+l}\right)\right)=0,
\end{aligned}
$$

where $\Lambda\left(s^{t+l}\right)$ is given by

$$
\Lambda\left(s^{t+l}\right)=\exp \left(e^{B}\left(s^{t+l}\right)\right) \beta^{t+l}\left(\frac{C\left(s^{t}\right)}{C\left(s^{t+l}\right)}\right) .
$$

Using equations (10), (11), and (12), the final goods $Y\left(s^{t}\right)$ produced in period $t$ are expressed with the wholesale goods produced in period $t$ as the following equation:

$$
y\left(s^{t}\right)=\int_{0}^{1} y\left(h, s^{t}\right) d h=\left[\int_{0}^{1}\left(\frac{P_{t}\left(h, s^{t}\right)}{P\left(s^{t}\right)}\right)^{-\epsilon} d h\right] Y\left(s^{t}\right) .
$$

Moreover, because of stickiness in the retail goods price, the aggregate price index for final goods $P\left(s^{t}\right)$ evolves according to the following law of motion:

$$
P\left(s^{t}\right)^{1-\epsilon}=(1-\xi) P^{*}\left(h, s^{t}\right)^{1-\epsilon}+\xi\left(\pi\left(s^{t-1}\right)^{\gamma_{p}} \bar{\pi}^{1-\gamma_{p}} P\left(s^{t-1}\right)\right)^{1-\epsilon} .
$$

\section{Wholesalers}

The wholesalers produce wholesale goods $y\left(s^{t}\right)$ and sell them to the retailers with the relative price $1 / X\left(s^{t}\right)$. They hire three types of labor inputs, $H\left(s^{t}\right), H^{F}\left(s^{t}\right)$, and $H^{E}\left(s^{t}\right)$, and borrow capital $K\left(s^{t-1}\right)$. These labor inputs are supplied by the household, the FIs, and the entrepreneurs for wages $W\left(s^{t}\right), W^{F}\left(s^{t}\right)$, and $W^{E}\left(s^{t}\right)$, respectively. Capital is supplied by the entrepreneurs with the rental price $R^{E}\left(s^{t}\right)$. At the end of each 
period, the capital is sold back to the entrepreneurs at price $Q\left(s^{t}\right)$. The maximization problem for the wholesaler is given by

$$
\begin{aligned}
\max _{y\left(s^{t}\right), K\left(s^{t-1}\right), H\left(s^{t}\right), H^{F}\left(s^{t}\right), H^{E}\left(s^{t}\right)} & \frac{1}{X\left(s^{t}\right)} y\left(s^{t}\right)+Q\left(s^{t}\right) K\left(s^{t-1}\right)(1-\delta) \\
& -R^{E}\left(s^{t}\right) Q\left(s^{t-1}\right) K\left(s^{t-1}\right)-W\left(s^{t}\right) H\left(s^{t}\right) \\
& -W^{F}\left(s^{t}\right) H^{F}\left(s^{t}\right)-W^{E}\left(s^{t}\right) H^{E}\left(s^{t}\right),
\end{aligned}
$$

subject to

$$
y\left(s^{t}\right)=A \exp \left(e^{A}\left(s^{t}\right)\right) K\left(s^{t-1}\right)^{\alpha} H\left(s^{t}\right)^{\left(1-\Omega_{F}-\Omega_{E}\right)(1-\alpha)} H^{F}\left(s^{t}\right)^{\Omega_{F}(1-\alpha)} H^{E}\left(s^{t}\right)^{\Omega_{E}(1-\alpha)},
$$

where $A \exp \left(e^{A}\left(s^{t}\right)\right)$ denotes the level of wholesale production technology and $\delta \in(0,1]$, $\alpha, \Omega_{F}$ and $\Omega_{E}$ are the depreciation rate of capital goods, the capital share, the share of the FIs' labor inputs, and the share of entrepreneurial labor inputs, respectively.

\section{Capital goods producers}

The capital goods producers own the technology that converts final goods to capital goods. In each period, the capital goods producers purchase $I\left(s^{t}\right)$ amounts of final goods from the final goods producers. In addition, they purchase $K\left(s^{t-1}\right)(1-\delta)$ of used capital goods from the entrepreneurs at price $Q\left(s^{t}\right)$. They then produce new capital goods $K\left(s^{t}\right)$, using the technology $F_{I}$, and sell them in the competitive market at price $Q\left(s^{t}\right)$. Consequently, the capital goods producer's problem is to maximize the following profit function:

$$
\max _{I\left(s^{t+l}\right)} \sum_{l=0}^{\infty} \mathrm{E}_{t} \Lambda\left(s^{t+l}\right)\left[Q\left(s^{t+l}\right)\left(1-F_{I}\left(I\left(s^{t+l}\right), I\left(s^{t+l-1}\right)\right)\right) I\left(s^{t+l}\right)-I\left(s^{t+l}\right)\right],
$$

where $F_{I}$ is defined as follows:

$$
F_{I}\left(I\left(s^{t+l}\right), I\left(s^{t+l-1}\right)\right) \equiv \frac{\kappa}{2}\left(\frac{\exp \left(e^{I}\left(s^{t+l}\right)\right) I\left(s^{t+l}\right)}{I\left(s^{t+l-1}\right)}-1\right)^{2} .
$$

Note that $\kappa$ is a parameter that is associated with investment technology with an adjustment cost, where $e^{I}\left(s^{t}\right)$ is the shock to the adjustment cost. ${ }^{13}$ Here, the development in the total capital available at period $t$ is described as

\footnotetext{
${ }^{13}$ Equation (14) does not include a term for the purchase of the used capital $K\left(s^{t-1}\right)$ from the entrepreneurs at the end of the period. This is because we assume, following BGG (1999), that the price of old capital that the entrepreneurs sell to the capital goods producers, say $\bar{Q}\left(s^{t}\right)$, is close to the price of the newly produced capital $Q\left(s^{t}\right)$ around the steady state.
} 


$$
K\left(s^{t}\right)=\left(1-F_{I}\left(I\left(s^{t}\right), I\left(s^{t-1}\right)\right)\right) I\left(s^{t}\right)+(1-\delta) K\left(s^{t-1}\right) .
$$

\section{Government}

The government collects a lump-sum tax from the household $T\left(s^{t}\right)$, and spends $G \exp \left(e^{G}\left(s^{t}\right)\right)$. A budget balance is maintained for each period $t$. Thus, we have

$$
G \exp \left(e^{G}\left(s^{t}\right)\right)=T\left(s^{t}\right)
$$

where $e^{G}\left(s^{t}\right)$ is the stochastic component of government spending.

\section{Monetary authority}

In our baseline model, the monetary authority sets the nominal interest rate $R^{n}\left(s^{t}\right)$, according to a standard Taylor rule with inertia ${ }^{14}$ :

$$
R^{n}\left(s^{t}\right)=\theta R^{n}\left(s^{t-1}\right)+(1-\theta)\left(\phi_{\pi} \pi\left(s^{t}\right)+\phi_{y} \log \left(\frac{G D P\left(s^{t}\right)}{G D P}\right)\right)+e^{R}\left(s^{t}\right),
$$

where $G D P\left(s^{t}\right)$ is defined as the sum of consumption, investment, and government expenditure, $\theta$ is the autoregressive parameter of the policy rate, $\phi_{\pi}$ and $\phi_{y}$ are the policy weight on inflation rate of final goods $\pi\left(s^{t}\right)$ and the output gap $\log \left(\frac{G D P\left(s^{t}\right)}{G D P}\right)$, respectively, and $e^{R}\left(s^{t}\right)$ is the shock to the monetary policy rule. Potential output is defined as the steady-state level of output, GDP. ${ }^{15}$ Because the monetary authority determines the nominal interest rate, the real interest rate in the economy is given by the following Fisher equation:

$$
R\left(s^{t}\right) \equiv \mathrm{E}_{t}\left\{\frac{R^{n}\left(s^{t}\right)}{\pi\left(s^{t+1}\right)}\right\}
$$

\section{Resource constraint}

The resource constraint for final goods is written as

$$
\begin{aligned}
Y\left(s^{t}\right)= & C\left(s^{t}\right)+I\left(s^{t}\right)+G \exp \left(e^{G}\left(s^{t}\right)\right) \\
& +\mu^{E} G^{E}\left(\bar{\omega}^{E}\left(s^{t}\right)\right) R^{E}\left(s^{t}\right) Q\left(s^{t-1}\right) K\left(s^{t-1}\right) \\
& +\mu^{F} G^{F}\left(\bar{\omega}^{F}\left(s^{t}\right)\right) R^{F}\left(s^{t}\right)\left(Q\left(s^{t-1}\right) K\left(s^{t-1}\right)-N^{E}\left(s^{t-1}\right)\right) \\
& +C^{F}\left(s^{t}\right)+C^{E}\left(s^{t}\right) .
\end{aligned}
$$

\footnotetext{
${ }^{14}$ In the current paper, we do not study the unconventional monetary policies conducted or discussed during the Great Recession. See HSU (2011) for the implication of some of the unconventional monetary policies, including the spread adjusted Taylor rules and the capital injection to the economy based on the chained-credit model.

${ }^{15}$ In addition to the current model, for sensitivity analysis we estimate the model in which the potential output is defined as the output achieved under flexible prices. Our quantitative results on the importance of the FIs' net worth shock are essentially unchanged under this alternative setting.
} 
Note that the fourth and the fifth terms on the right-hand side of the equation represent the monitoring costs incurred by the FIs and the investors, respectively. The last two terms are the FIs' and the entrepreneurs' consumption.

\section{Law of motion for non-financial exogenous variables}

There are five equations for the shock processes, $e^{A}\left(s^{t}\right), e^{I}\left(s^{t}\right), e^{B}\left(s^{t}\right), e^{G}\left(s^{t}\right)$, and $e^{R}\left(s^{t}\right)$, following processes as below:

$$
\begin{gathered}
e^{A}\left(s^{t}\right)=\rho_{A} e^{A}\left(s^{t-1}\right)+\varepsilon^{A}\left(s^{t}\right), \\
e^{I}\left(s^{t}\right)=\rho_{I} e^{I}\left(s^{t-1}\right)+\varepsilon^{I}\left(s^{t}\right), \\
e^{B}\left(s^{t}\right)=\rho_{\beta} e^{B}\left(s^{t-1}\right)+\varepsilon^{B}\left(s^{t}\right), \\
e^{G}\left(s^{t}\right)=\rho_{G} e^{G}\left(s^{t-1}\right)+\varepsilon^{G}\left(s^{t}\right), \\
e^{R}\left(s^{t}\right)=\rho_{R} e^{R}\left(s^{t-1}\right)+\varepsilon^{R}\left(s^{t}\right),
\end{gathered}
$$

where $\rho_{A}, \rho_{I}, \rho_{B}, \rho_{G}$, and $\rho_{R} \in(0,1)$ are autoregressive roots of the exogenous variables, and $\varepsilon^{A}\left(s^{t}\right), \varepsilon^{I}\left(s^{t}\right), \varepsilon^{B}\left(s^{t}\right), \varepsilon^{G}\left(s^{t}\right)$, and $\varepsilon^{R}\left(s^{t}\right)$ are innovations that are mutually independent, serially uncorrelated, and normally distributed with mean zero and variances $\sigma_{A}^{2}, \sigma_{I}^{2}, \sigma_{\beta}^{2}, \sigma_{G}^{2}$, and $\sigma_{R}^{2}$, respectively.

\subsection{Equilibrium Condition}

An equilibrium consists of a set of prices, $\left\{P\left(h, s^{t}\right)\right.$ for $h \in[0,1], P\left(s^{t}\right), X\left(s^{t}\right), R\left(s^{t}\right)$, $R^{F}\left(s^{t}\right), R^{E}\left(s^{t}\right), W\left(s^{t}\right), W^{F}\left(s^{t}\right), W^{E}\left(s^{t}\right), Q\left(s^{t}\right), R^{F}\left(s^{t+1} \mid s^{t}\right), R^{E}\left(s^{t+1} \mid s^{t}\right), Z^{F}\left(s^{t+1} \mid s^{t}\right)$, $\left.Z^{E}\left(s^{t+1} \mid s^{t}\right)\right\}_{t=0}^{\infty}$, and the allocations $\left\{\bar{\omega}^{F}\left(s^{t+1} \mid s^{t}\right)\right\}_{t=0}^{\infty},\left\{\bar{\omega}^{E}\left(s^{t+1} \mid s^{t}\right)\right\}_{t=0}^{\infty},\left\{N^{F}\left(s^{t}\right)\right\}_{t=0}^{\infty}$, $\left\{N^{E}\left(s^{t}\right)\right\}_{t=0}^{\infty}\left\{\left\{y\left(h, s^{t}\right)\right), Y\left(h, s^{t}\right)\right.$ for $h \in[0,1], Y\left(s^{t}\right), G D P\left(s^{t}\right), C\left(s^{t}\right), D\left(s^{t}\right), I\left(s^{t}\right)$, $\left.\left.K\left(s^{t}\right), H\left(s^{t}\right), H^{F}\left(s^{t}\right), H^{E}\left(s^{t}\right)\right\}\right\}_{t=0}^{\infty}$, for a given government policy $\left\{R^{n}\left(s^{t}\right), G_{t}\left(s^{t}\right)\right.$, $\left.T\left(s^{t}\right)\right\}_{t=0}^{\infty}$, realization of exogenous variables $\left\{\varepsilon^{A}\left(s^{t}\right), e^{B}\left(s^{t}\right), e^{G}\left(s^{t}\right), e^{I}\left(s^{t}\right), \varepsilon^{R}\left(s^{t}\right)\right.$, $\left.\varepsilon^{N^{E}}\left(s^{t}\right), \varepsilon^{N^{F}}\left(s^{t}\right)\right\}_{t=0}^{\infty}$ and initial conditions $N_{-1}^{F}, N_{-1}^{E}, K_{-1}$ such that for all $t$ and $h$ :

(1) the household maximizes its utility given the prices;

(2) the FIs maximize their profits given the prices;

(3) the entrepreneurs maximize their profits given the prices;

(4) the final goods producers maximize their profits given the prices;

(5) the retail goods producers maximize their profits given the prices;

(6) the wholesale goods producers maximize their profits given the prices;

(7) the capital goods producers maximize their profits given the prices;

(8) the government budget constraint holds; and

(9) markets clear. 


\section{Estimation}

Following Christensen and Dib (2008), we set some of the parameters to the values used in the existing studies. These include the quarterly discount factor $\beta$, the quarterly depreciation rate $\delta$, the capital share $\alpha$, the risk-free rate $R$, the degree of substitutability $\epsilon$, the labor supply elasticity $\eta$, the utility weight of labor $\chi$, and the steady state share of government expenditure in final goods output $G / Y$. See Table 1-1 for the values of these parameters.

We estimate the rest of parameters of the model using a Bayesian method. Estimated parameters are the frequency of price adjustment $\xi_{p}$, a parameter that controls the capital adjustment cost $\kappa$, the degree of price indexation $\gamma_{p}$, the coefficients of the policy rule $\theta, \phi_{\pi}$ and $\phi_{y}$, the autoregressive parameters of the shock process $\rho_{A}, \rho_{I}, \rho_{B}, \rho_{G}$, and $\rho_{R}$, the variances of these shocks $\sigma_{A}^{2}, \sigma_{I}^{2}, \sigma_{B}^{2}, \sigma_{G}^{2}$, and $\sigma_{R}^{2}$, as well as the variances of the shocks to net worth $\sigma_{N^{F}}^{2}$ and $\sigma_{N^{E}}^{2}$. In addition, we also estimate the six financial parameters, the lenders' monitoring cost in the IF contract $\mu^{F}$, the lenders' monitoring cost in the FE contract $\mu^{E}$, the standard deviation of the idiosyncratic productivity shock in the FI sector $\sigma_{F}$, the standard deviation of the idiosyncratic productivity shock in the entrepreneurial sector $\sigma_{E}$, the survival rate of the FIs $\gamma^{F}$, and the survival rate of the entrepreneurs $\gamma^{E}$.

To calculate the posterior distribution and to evaluate the marginal likelihood of the model, the Metropolis-Hastings algorithm is employed. To do this, a sample of 200,000 draws was created, neglecting the first 100,000 draws. ${ }^{16}$

\subsection{Data}

Our benchmark dataset includes seven time series for the U.S. economy from 1984Q1 to 2010Q4: namely, real GDP, real consumption, real investment, the log difference of the GDP deflator, the federal funds (FF) rate, the sum of the net worth of the FI sector and the entrepreneurial sector, and the net worth of the FI sector. Following CMR (2008, 2009), we use the S\&P500 stock index and the S\&P SPRCM Banks Index as our measure of the total net worth and the FIs' net worth, respectively. ${ }^{17}$ In addition to this benchmark dataset, we incorporate two additional credit spread series into the dataset and reestimate the model in our sensitivity analysis reported in Section 3.5. There, we employ the time series of the $\mathrm{CD}$ rate minus the $\mathrm{FF}$ rate, and the BAA corporate

\footnotetext{
${ }^{16}$ All estimations are done with Dynare.

${ }^{17}$ Admittedly, the equity series reported in the Flow of Funds Account rather than the stock price series may also well track the movement of the net worths. In addition to the estimation using the stock price series as the model's net worth series, we estimate the model using the equity series reported in the Flow of Funds Accounts. As far as the quantitative roles of the financial shocks in the investment variations are concerned, these two estimation strategy yield the similar result. See the early version of our paper, HSU (2010), for details.
} 
bond rate minus the FF rate, as our measures of the spreads $Z^{F}\left(s^{t+1} \mid s^{t}\right)-R\left(s^{t}\right)$ and $Z^{E}\left(s^{t+1} \mid s^{t}\right)-R\left(s^{t}\right)$ in the model. ${ }^{18}$

All of the variables other than the log difference of the GDP deflator, the FF rate and the two spreads, when used, are first differenced. Following CMR (2008, 2009), we impose the condition that for each of the endogenous variables, the mean in the model coincides with the mean in the data. In estimating the model, therefore, we remove the sample mean of the growth rate of real GDP, real consumption, real investment, net worth, the level of the FF rate, and the log difference of the GDP deflator. We depict all data series used in the estimation in Figure 1.

\subsection{Prior and Posterior Distribution of the Parameters}

\section{Prior distribution of the non-financial parameters}

Table 2 reports the results of the parameter estimates. The adjustment cost parameter for investment $\kappa$ is normally distributed with a mean of 4.0 and a standard deviation of 1.5 ; the Calvo probability $\xi_{p}$ is beta distributed with a mean of 0.5 and a standard deviation of 0.15 ; the degree of indexation to past inflation $\gamma_{p}$ is beta distributed with a mean of 0.5 and a standard deviation of 0.2 ; the policy weight on the lagged policy rate $\theta$ is normally distributed with a mean of 0.75 and a standard deviation of 0.1 ; the policy weight on the inflation $\phi_{\pi}$ is normally distributed with a mean of 1.5 and a standard deviation of 0.125 ; and the policy weight on the output gap $\phi_{y}$ is normally distributed with a mean of 0.125 and a standard deviation of 0.05 .

The priors on the stochastic processes of the exogenous shocks are set to follow an $\operatorname{AR}(1)$ process with autoregressive parameters $\rho_{A}, \rho_{I}, \rho_{B}, \rho_{G}$, and $\rho_{R}$, which are beta distributed with a mean of 0.5 and a standard deviation of 0.2 . The variances of the innovations in exogenous variables $\sigma_{A}^{2}, \sigma_{I}^{2}, \sigma_{\beta}^{2}, \sigma_{G}^{2}, \sigma_{N^{F}}^{2}, \sigma_{N^{E}}^{2}$, and $\sigma_{R}^{2}$ are assumed to follow an inverse-gamma distribution with a mean of 0.01 .

\section{Prior mean of the financial parameters}

To set the prior mean of the six financial parameters, we use the following equilibrium conditions

(1) the spread between the return to capital and the risk-free rate, $R^{E}-R$, equals to $2 \%$ annually;

(2) the ratio of net worth held by the FIs to capital, $N^{F} / Q K$, is 0.1 ;

(3) the ratio of net worth held by entrepreneurs to capital, $N^{E} / Q K$, is 0.5 ;

(4) the annualized failure rate of the FIs is $3 \%$;

(5) the annualized failure rate of the entrepreneurs is $3 \%$;

\footnotetext{
${ }^{18}$ We hereafter call the two spreads the FIs' borrowing spread and the entrepreneurial borrowing spread, respectively.
} 
(6) the ratio of the spread between the FIs' lending rate and the FIs' borrowing rate, $Z^{E}-Z^{F}$, to the spread between the FIs' borrowing rate and the risk-free rate, $Z^{F}-R$, equals $337 \mathrm{bps} / 58 \mathrm{bps}$.

The conditions (1), (3), (4), and (5) are borrowed from BGG (1999). To obtain condition (2), we construct the corresponding time series for $N^{F} / Q K$ from the FIs' net worth divided by the total net worth, and take its historical average, based on the Flow of Funds Accounts. ${ }^{19}$ To obtain condition (6), we construct the historical average of the ratio from 1980 to 2008, using the BAA yield, the 3-months CD rate, and the 3-months TIBOR as proxy for the FI's lending rate $Z^{E}$, the FIs' borrowing rate $Z^{F}$, and the riskfree rate $R$, respectively. See Table 1-2 for detail. The standard deviation of the financial parameters are slightly narrow, $0.010,0.002,0.005$, and 0.010 , respectively.

\section{Posterior Distribution}

The last three columns in Table 2 display the posterior mean and the confidence intervals of the model parameters. ${ }^{20}$ For the investment adjustment cost, we obtain $\kappa=7.21$. This value falls between the estimates of 0.65 (Meier and Muller, 2006) and 32.1 (Ireland, 2003) in existing studies. Our estimates of the Calvo probability and degree of indexation are $\xi_{p}=0.79$ and $\gamma_{p}=0.08$, respectively. The degree of nominal price rigidity implied from these parameter values is smaller than the findings in Meier and Muller (2006). The estimated monetary policy rule exhibits aggressive response to current inflation $\phi_{\pi}=1.52$, with inertia of the interest rate $\theta=0.77$, and a mild response to current output $\phi_{y}=0.05$.

In estimating the six financial parameters, we assume that conditions (2) and (3) hold. Estimates of the parameters are $\mu^{F}=0.065$ and $\mu^{E}=0.015$ for the monitoring costs, $\sigma_{F}=0.082$ and $\sigma_{E}=0.266$ for the standard deviation of the idiosyncratic productivities, and $\gamma^{F}=0.96$ and $\gamma^{E}=0.98$ for the survival rates. The steady-state spreads implied from the estimated parameters are $0.94 \%$ for the spread between the return to capital and the risk-free rate $R^{E}-R, 1.15 \%$ for the entrepreneurial borrowing spread $Z^{E}-R$, and $0.11 \%$ for the FIs' borrowing spread $Z^{F}-R$, in an annual rate, indicating that the bulk of external finance premium arises from the spread between the entrepreneurial borrowing rate and the FI's borrowing rate.

The table also includes the shock processes of the seven exogenous variables. The government expenditure, productivity, and the preference processes are estimated to be persistent with $\mathrm{AR}(1)$ coefficients of $0.96,0.95$, and 0.90 , respectively. The laws of motion for the investment adjustment cost and the monetary policy rate are 0.81 and 0.24 , which are relatively less persistent.

\footnotetext{
${ }^{19}$ Here, the FIs' net worth and the entrepreneurial net worth are calculated from "corporate equities + equity in the noncorporate business sector" issued by the financial business sector and "corporate equities + equity in the noncorporate business sector" issued by the nonfinancial business sector, respectively.

${ }^{20}$ See also Figure 2, where the posterior distributions of the model parameters (depicted in the thick red line) are displayed with the prior distribution of the parameters (depicted in the thin black line).
} 


\subsection{Impulse Responses}

To illustrate the role played by the shocks to the FIs' net worth $N^{F}\left(s^{t}\right)$, Figure 3 plots the economic responses to a negative shock to the net worth by one unit. The red dotted line and the black line display the economy's response to a shock to the entrepreneurial net worth and the economy's response to a shock to the FIs' net worth, respectively. An adverse shock to the net worth causes the downturn in the macroeconomy. The FIs' low net worth widens the two spreads, thereby reducing investment and output. Since a limited borrower's net worth yields a higher leverage and default probability of the borrowing sectors, the external finance becomes more costly than otherwise. Consequently, the two credit spreads, the entrepreneurial borrowing spread and the FIs' borrowing spread, $Z^{E}\left(s^{t+1} \mid s^{t}\right)-R\left(s^{t}\right)$ and $Z^{F}\left(s^{t+1} \mid s^{t}\right)-R\left(s^{t}\right)$, widen, dampening investment and output. Although the shock to the net worth is a one-time shock and therefore has no inertia, its impacts on the economy are persistent. That is, as the demand for capital goods $K\left(s^{t}\right)$ is weakened, the capital price $Q\left(s^{t}\right)$ falls, leading to a further decrease in the investment owing to the endogenous declines in the entrepreneurial net worth as well as the FIs' net worth.

For the purpose of comparison, we also depict impulse responses to a unit negative shock to the entrepreneurial net worth $N^{E}\left(s^{t}\right)$. Time paths of the variables after the shock are similar to those after the shock to the FIs' net worth, but smaller. As pointed out in HSU (2009), for the same size of the shock, a shock to the FIs' net worth has a greater economic consequence than that to the entrepreneurial net worth.

\subsection{Importance of Shocks to the FI Sector}

\section{Description of the time series of the shocks to the FIs' net worth}

We now study how the shocks to the FIs' net worth affect the credit market and the real economy throughout the sample period. Figure 4 displays the time series of the seven structural shocks together with the National Bureau of Economic Research (NBER) business cycle periods. The realizations of the FIs' net worth shocks are cyclical, typically taking large negative values during the recession. Particularly, during the Great Recession, several quarters since 2007, the exogenous net worth decline in the FI sector has been unprecedentedly deep and persistent.

Compared with the shocks to entrepreneurial net worth that are also depicted in Figure 4, variations of shocks to the FIs' net worth are relatively moderate. Although the two shock series sometimes move differently over the sample period, they simultaneously drop substantially at the outset of the Great Recession.

Both shock series are negatively correlated with the financial indicators of credit market stress. For example, the contemporaneous correlations of each of the two shock series, the shocks to the FIs' net worth and those to the entrepreneurial net worth, and the BAA corporate bond rate minus the FF rate are 0.22 and 0.30 , respectively. That 
indicates the link between the decline in the net worth in the borrowing sector and financial stress.

\section{The role played by the shocks to the FIs' net worth}

The shocks to the FIs' net worth bring about variations in both financial variables and real variables. In Figures 5 and 6, we depict the model-generated time path of the FIs' borrowing spread $Z^{F}\left(s^{t+1} \mid s^{t}\right)-R\left(s^{t}\right)$ and the entrepreneurial borrowing spread $Z^{E}\left(s^{t+1} \mid s^{t}\right)-R\left(s^{t}\right)$ by the black line, and the actual time path of the data counter parts by the red line with circle. ${ }^{21}$ The two model-generated series have strong co-movement with the corresponding actual time series. The contemporaneous correlation between $Z^{F}\left(s^{t+1} \mid s^{t}\right)-R\left(s^{t}\right)$ and the three-month CD rate minus the FF rate is 0.56 , and that between $Z^{E}\left(s^{t+1} \mid s^{t}\right)-R\left(s^{t}\right)$ and the BAA corporate bond rate minus the FF rate is 0.62 , respectively. ${ }^{22}$

Figure 7 displays the time path of investment. To see the role played by the shocks to FIs' net worth in detail, we decompose the investment variations into the proportions explained by each of the financial shocks and the non-financial shocks. In the six panels, the solid blue line depicts the investment growth and white bar depicts a shock's contribution. $^{23}$

Among the three episodes of the economic downturn, the shocks to the FIs' net worth are the main driving force behind the investment decline during the first and third recessions. In particular, in the Great Recession that begins with financial turmoil and the collapse of FI institutions, their negative impacts are unprecedentedly large, lowering the investment for nearly three years. By contrast, in the second recession following the bursting of the dot-com bubble, the shocks barely play any role.

To assess the significance of the FIs' net worth shock relative to other shocks, we compute the historical decomposition for variations of investment together with those of other economic variables. ${ }^{24}$ Tables 3-1 and 3-2 display the variance decomposition of the FIs' borrowing spread $Z^{F}\left(s^{t+1} \mid s^{t}\right)-R\left(s^{t}\right)$, the entrepreneurial borrowing spread $Z^{E}\left(s^{t+1} \mid s^{t}\right)-Z^{F}\left(s^{t+1} \mid s^{t}\right)$, GDP GDP $\left(s^{t}\right)$, investment $I\left(s^{t}\right)$, and inflation $\pi\left(s^{t}\right)$ for the periods during the Great Recession and after (2007Q1:2010Q4) as well as for the entire sample period.

\footnotetext{
${ }^{21}$ In the analysis for both model-implied series and the related actual data, we focus on their businesscycle components (six quarters to 32 quarters) and extract these components by applying the band-pass filter to the original series.

${ }^{22}$ Here, the three-month CD rate and the BAA corporate bond rate serve as the proxy for the FIs' borrowing rate and the entrepreneurial borrowing rate. The corresponding data series for $R\left(s^{t}\right)$ is calculated as the policy rate divided by the aggregate price level in the model.

${ }^{23}$ For the preference shocks $\varepsilon_{t}^{B}$ and the exogenous spending shocks $\varepsilon_{t}^{G}$, we report only sum of the contributions because their quantitative impacts are relatively small.

${ }^{24}$ In calculating the variance decompositions, we first calculate the historical variance of a modelgenerated endogenous variable when only one of the shocks is fed into the model. We then sum these variances to calculate the share of each shock in explaining the variations of the endogenous variables.
} 
In the period of the Great Recession and after, the shocks to the FIs' net worth are the main driver behind the reduction in the investment and the widening of the entrepreneurial borrowing spread variation, accounting for $36 \%$ and $46 \%$ of their variations. The severe deterioration in the FIs' net worth at that time causes a drastic widening of the entrepreneurial borrowing spread, leading to a quantitatively significant scale of investment decline. This quantitative result is consistent with the peculiar feature of the Great Recession that involves the financial market turmoil and the collapses of major banking institutions. ${ }^{25}$

Over the U.S. business cycles, the shocks to the FIs' net worth are one of the important sources of the investment variations and the entrepreneurial borrowing spread variations. The shock is the third largest contributor of the investment variations and the second largest contributor of the entrepreneurial borrowing spread variations, accounting for $17 \%$ and $35 \%$ of the variations, respectively.

By contrast, its quantitative impact on the other economic variables is minor. They explain only $4 \%$ of the variations in output and inflation, and $10 \%$ of the variations in the FIs' borrowing spread.

\section{The role played by the other shocks}

The shock to the entrepreneurial net worth is also quantitatively important for the business cycle. Over the entire sample period, it is the key determinant of investment dynamics, accounting for $38 \%$ of the variations. In particular, in the recession following the bursting of the dot-com bubble, the shocks generate the bulk of investment reduction. In the Great Recession, it is the second largest driver of the investment decline, accounting for $28 \%$ of the variations. Together with the shocks to the FIs' net worth, the shocks explain more than half of the investment variations since the mid-1980s, suggesting the importance of the financial shocks in the U.S. economy.

Similarly to the shocks to the FIs' net worth, the contribution of the shocks to the entrepreneurial net worth in output and inflation variations is relatively minor. In the current model, these variables are mostly explained by the preference shocks and technology shocks.

\subsection{Sensitivity Analysis}

We have seen up to now that shocks to the FI sector play a quantitatively important role, particularly in the U.S. investment variations. In our analysis, we have assumed that financial shocks originating in the FI sector take the form of exogenous change in the FIs' net worth, and that our benchmark dataset is sufficient to identify these shocks. In this section, we conduct sensitivity tests by incorporating another type of financial

\footnotetext{
${ }^{25}$ Comapred with our earlier version HSU (2010), we obtain a larger contribution of FIs' net worth shock to investment during the recent financial crisis and a smaller contribution before that period. These differences arise for two reasons. First and most importantly, we use the stock price index as a proxy for net worth. Second, we estimate parameters associated with credit markets.
} 
shock to the FI sector as well as the net worth shock, and by including the spread series in the dataset of estimation so as to see the identified financial shocks are unchanged.

First, while most of the studies on banking shocks concentrate on the shocks that directly change FIs' net worth, ${ }^{26}$ we consider a different type of exogenous shock, "riskiness shocks," along with the shocks to the net worth. CMR (2008, 2009) study the economy in which credit market imperfection is worsened by the exogenous increase in the variance of borrowers' idiosyncratic productivity called "riskiness." Realization of the riskiness shock is independent of the net worth shock, and the shock captures the variations in the external finance premium that does not stem from the exogenous net worth variations. Closely following $\operatorname{CMR}$ (2008, 2009), we now assume that the standard deviations of idiosyncratic productivity shocks of borrowers are time-variant, so that $\sigma_{F}\left(s^{t}\right)$ and $\sigma_{E}\left(s^{t}\right)$ obey the laws of motion:

$$
\begin{aligned}
& \log \left(\frac{\sigma_{F}\left(s^{t}\right)}{\bar{\sigma}_{F}}\right)=\rho_{\sigma_{F}} \log \left(\frac{\sigma_{F}\left(s^{t-1}\right)}{\bar{\sigma}_{F}}\right)+\varepsilon^{\sigma_{F}}\left(s^{t}\right), \\
& \log \left(\frac{\sigma_{E}\left(s^{t}\right)}{\bar{\sigma}_{E}}\right)=\rho_{\sigma_{E}} \log \left(\frac{\sigma_{E}\left(s^{t-1}\right)}{\bar{\sigma}_{E}}\right)+\varepsilon^{\sigma_{E}}\left(s^{t}\right),
\end{aligned}
$$

where $\rho_{\sigma_{F}}$ and $\rho_{\sigma_{E}}$ are autoregressive parameters, $\varepsilon^{\sigma_{F}}\left(s^{t}\right)$ and $\varepsilon^{\sigma_{E}}\left(s^{t}\right)$ are the corresponding innovations, and $\bar{\sigma}_{F}$ and $\bar{\sigma}_{E}$ are the steady state values of riskiness. As shown in $\operatorname{HSU}(2009,2011)$, a rise in either $\sigma_{F}\left(s^{t}\right)$ or $\sigma_{E}\left(s^{t}\right)$ increases the payment to the lender, causing a higher external finance premium and a downturn in investment, even when there are no variations in the net worth.

Second, we reformulate the estimation using the spread data. In the benchmark estimation, we choose not to employ the spread series in identifying shocks, because the data series representing overall financial conditions of the FIs and entrepreneurs that are needed for constructing the spread series matching our spreads series $Z^{F}\left(s^{t+1} \mid s^{t}\right)-R\left(s^{t}\right)$ and $Z^{E}\left(s^{t+1} \mid s^{t}\right)-R\left(s^{t}\right)$ are not available. In fact, the choice of observable variables used for estimating the financial accelerator model differs across studies. For instance, while Christensen and Dib (2008) and De Graeve (2008) employ neither series in estimation, Nolan and Thoenissen (2009) use only net worth series but not the spread series. By contrast, CMR $(2008,2009)$ employ the spread series, the BAA-AAA yield on corporate bonds as a measure of external finance premium in estimation, to distill financial shocks to the credit market. The second sensitivity check thus intends to see how our results change if spread series are added to the estimation.

We conduct two alternative formulations, estimation I and estimation II. In estimation I, the dataset for the estimation $\left\{C_{t}, G D P_{t}, I_{t}, R_{t}^{n}, \pi_{t}, N_{t}^{F}+N_{t}^{E}, N_{t}^{E}\right.$, $\left.Z_{t}^{F}-R_{t}, Z_{t}^{E}-R_{t}\right\}_{t=1984 Q 1}^{2010 Q 4}$ includes the two spread series, the CD rate minus the FF rate for $Z^{F}\left(s^{t+1} \mid s^{t}\right)-R\left(s^{t}\right)$ and the BAA corporate bond rate minus the $\mathrm{FF}$ rate for

\footnotetext{
${ }^{26}$ See, for example, Chen (2001), Meh and Moran (2004), and Aikman and Paustian (2006).
} 
$Z^{E}\left(s^{t+1} \mid s^{t}\right)-R\left(s^{t}\right)$, respectively. In addition, the estimated model incorporate the riskiness shocks as well as the net worth shocks. This approach is close to CMR (2008, 2009). In estimation II, the same dataset used in the benchmark estimation is utilized. Again, the model incorporates the riskiness shocks as well as the net worth shocks. This approach also encompasses CMR (2008, 2009), who argue for the importance of the riskiness shock.

The results are shown in Table 4. The estimated impact of the shocks to the FI sector is robust to incorporating the other type of shock to the FI, and to including the spread data into the dataset. The contribution of shocks to FIs' net worth amounts to $12 \%$ and $17 \%$ in the investment variations in estimations I and II, respectively. ${ }^{27}$

\subsection{Importance of Chained Credit Contracts}

In contrast to the existing financial accelerator models, our model introduces the endogenous developments in the FIs' net worth and credit market imperfection that originates from them. To illustrate the implication of this additional source of the financial accelerator effect, we conduct two comparison analyses in this last subsection.

First, we examine if our model fits the data, compared with the model that abstracts from the credit market imperfection in the FI sector. To do this, we develop a model called the "BGG model" in which the entrepreneurs are credit constrained but the FIs are not. ${ }^{28}$ We then estimate the BGG model and our benchmark model, using the same dataset $\left\{C_{t}, G D P_{t}, I_{t}, R_{t}^{n}, \pi_{t}, N_{t}^{E}\right\}_{t=1984 Q 1}^{2010 Q 4}$ to see which model better explains the data.

The results of this estimation are shown in Table $5 .{ }^{29}$ The value of the log marginal data density under the BGG model is lower than that under the benchmark model, implying that the latter is more successful in explaining the set of the time series $\left\{C_{t}\right.$, $\left.G D P_{t}, I_{t}, R_{t}^{n}, \pi_{t}, N_{t}^{E}\right\}_{t=1984 Q 1}^{2010 Q 4}$. Given equal prior odds, the posterior odds ratios of the benchmark model and the BGG model are 0.93 and 0.07 , respectively. Since the two models differ only in the financial accelerator effect stemming from the FIs' net worth,

\footnotetext{
${ }^{27}$ In contrast to the net worth shocks, the riskiness shocks explain only a small fraction of the investment variations. This contrasts sharply with CMR (2009) where such shock explains a sizable portion of the variations. In their paper, the riskiness shock consists of anticipated components as well as the contemporaneous unexpected components, and one possible explanation for the difference between their result and ours is that the anticipated component of the riskiness plays an important role in the investment variations.

${ }^{28}$ This BGG model employs the same setting as the financial accelerator model of BGG (1999). The only difference is that, in our BGG model, we estimate the most of the model parameters rather than calibrate them. A full description of the BGG model is provided in Appendix C. We estimate parameters $\left\{\xi_{p}, \kappa, \gamma_{p}, \sigma^{E}, \mu^{E}, \gamma^{E}, \theta, \phi_{\pi}, \phi_{y}\right\}$ and shock processes $\left\{\rho_{A}, \rho_{I}, \rho_{B}, \rho_{G}, \rho_{R}, \sigma_{A}, \sigma_{I}, \sigma_{B}, \sigma_{G}, \sigma_{R}, \sigma_{N^{E}}\right\}$, using the dataset $\left\{C_{t}, G D P_{t}, I_{t}, \pi_{t}, R_{t}^{n}, N_{t}^{E}\right\}_{t=1984 Q 1}^{2010 Q 4}$. The rest of the parameters are calibrated to the U.S. economy.

${ }^{29}$ In estimating the benchmark model, we do not use the data of the FIs' net worth, so that the outcomes are comparable between the BGG model and the benchmark model.
} 
the difference in the log marginal data density shows the importance of the IF contract that is chained to the FE contracts in explaining the data. ${ }^{30}$

Second, we ask if introducing shocks to the FIs' net worth changes our understanding of the source of the investment variations. Early studies that abstract from the shocks originating in the credit market report that a bulk of economic variations is attributed to the shocks to the investment technology. According to Christensen and Dib (2008), more than $90 \%$ of investment variations originate in the shocks to investment efficiency. On the other hand, Nolan and Thoenissen (2009), based on the model that does not incorporate shocks to the investment technology, report that financial shocks originating in the credit market are important. Because our model has both financial shocks to the credit market $\varepsilon_{t}^{N^{E}}$ and $\varepsilon_{t}^{N^{F}}$, and the non-financial shocks that directly affect the investment adjustment $\operatorname{cost}$ technology $\varepsilon_{t}^{I}$, we can separate the contributions of the former shocks from those of the latter shocks.

To illustrate the role played by the shocks to the FIs' net worth, we estimate one other model, which we call the "Non-FA (Non financial accelerator) model," ${ }^{1}$ where no credit market imperfection prevails in the economy, along with the BGG model and the benchmark model by a Bayesian method. ${ }^{32}$ Table 6 reports the variance decompositions of investment variations under the three models. Under the Non-FA model, a bulk of the variations, $74 \%$, comes from the shocks to investment adjustment $\operatorname{cost} \varepsilon_{t}^{I}$, being in line with the findings reported in Christensen and Dib (2008). When financial shocks originating in the credit market are incorporated into the model, however, the estimated contribution of the non-financial shocks become lower. The contribution of shocks to the investment adjustment cost technology $\varepsilon_{t}^{I}$ is reduced to $51 \%$ and $28 \%$, respectively, in the BGG model and the benchmark model. By contrast, a portion of investment variations attributed to the financial shocks become larger. In the BGG model, the shock to entrepreneurial net worth accounts for $22 \%$ of the investment variations. In the benchmark model, the two financial shocks account for $55 \%$ of the variations. Clearly, the financial shocks are the key determinant of investment variations, though the nonfinancial shocks are not negligible source of the variations.

\section{Conclusion}

In this paper, we quantitatively assess the role played by the shocks to the FIs' net worth in the U.S. business cycle. To this end, we estimate and simulate the financial accelerator

\footnotetext{
${ }^{30}$ Christensen and Dib (2008) conclude using the log-likelihood ratio test that their financial accelerator model outperforms the model that abstracts from the financial accelerator effect.

${ }^{31}$ We provide a full description of the Non-FA model in Appendix C. For the Non-FA model, we estimate parameters $\left\{\kappa, \xi, \gamma_{p}, \theta, \phi_{\pi}, \phi_{y}\right\}$ and shock processes $\left\{\rho_{A}, \rho_{I}, \rho_{B}, \rho_{G}, \rho_{R}, \sigma_{A}, \sigma_{I}, \sigma_{B}, \sigma_{G}\right.$, $\left.\sigma_{R}\right\}$, , using the data set $\left\{C_{t}, G D P_{t}, I_{t}, \pi_{t}, R_{t}^{n}\right\}_{t=1984 Q 1}^{2010 Q 4}$. The rest of the parameters are calibrated to the U.S. economy.

${ }^{32}$ In estimating the benchmark model, we employ the full dataset including the FIs' net worth.
} 
model in HSU $(2009,2011)$, in which FIs along with entrepreneurs are credit constrained. In this model, once net worth in the FI sector falls, the cost of external finance increases, reducing investment. Consequently, endogenous developments in the FIs' net worth as well those in the entrepreneurial net worth become a key to the amplification and propagation mechanism in the economy.

Employing a Bayesian method, we distill the shocks to the FIs' net worth from the U.S. dataset that includes the FIs' net worth. These shocks typically take negative values during a recession, particularly during the Great Recession that began in 2007. We find that the shocks to the FI sector play an important role behind the investment variations. In particular, in the Great Recession, these shocks are the key driving force of the investment collapse, accounting for $36 \%$ for investment variations during the period. The quantitative role of these shocks is minor in the variations of the other variables, such as output and inflation, contributing about $4 \%$ of their variations.

Extending the current model to other dimensions may help achieve a clearer idea of the relationship between the financial market and the macroeconomy. First, it is important to incorporate the interbank market into the model. While the current model abstracts from the market, the repayment failure in the credit contracts between the FIs and the subsequent collapse of the financial system was a common concern of the market participants and policy makers at that time. Second, future work needs to address why the financial shocks in our model play a limited role in explaining macroeconomic variables other than investment. As current research by CMR (2009) suggests, consideration for anticipated components of the financial shocks may lead to a better understanding of the linkage between the financial sector and the economy. 


\section{A Credit Contract}

In this section, we discuss how the contents of the two credit contracts are determined by the profit maximization problem of the FIs. We first explain how the FIs earn profit from the credit contracts, and then explain the participation constraints of the other participants in the credit contracts.

In each period $t$, the expected net profit of an FI from the credit contracts is expressed by

$$
\sum_{s^{t+1}} \Pi\left(s^{t+1} \mid s^{t}\right) \overbrace{\left[1-\Gamma^{F}\left(\bar{\omega}^{F}\left(s^{t+1} \mid s^{t}\right)\right)\right]}^{\text {share of FIs earnings received by the FI }} R^{F}\left(s^{t+1} \mid s^{t}\right)\left(Q_{t}\left(s^{t}\right) K\left(s^{t}\right)-N^{E}\left(s^{t}\right)\right),
$$

where $\Pi\left(s^{t+1} \mid s^{t}\right)$ is a probability weight for state $s^{t+1}$ for given state $s^{t}$. Here, the expected return on the loans to entrepreneurs, $R^{F}\left(s^{t+1} \mid s^{t}\right)$ is given by

$$
\begin{gathered}
\overbrace{\left[\Gamma^{E}\left(\bar{\omega}^{E}\left(s^{t+1} \mid s^{t}\right)\right)-\mu^{E} G^{E}\left(\bar{\omega}^{E}\left(s^{t+1} \mid s^{t}\right)\right)\right]}^{\text {share of entrepreneurial earnings received by the FI }} R^{E}\left(s^{t+1} \mid s^{t}\right) Q\left(s^{t}\right) K\left(s^{t}\right) \\
\equiv R^{F}\left(s^{t+1} \mid s^{t}\right)\left(Q\left(s^{t}\right) K\left(s^{t}\right)-N^{E}\left(s^{t}\right)\right) \text { for } \forall s^{t+1} \mid s^{t} .
\end{gathered}
$$

This equation indicates that the two credit contracts determine the FIs' profits. In the FE contract, the FIs receive a portion of what entrepreneurs earn from their projects as their gross profit. In the IF contract, the FIs receive a portion of what they receive from the FE contract as their net profit, and pay the rest to the investors.

There is a participation constraint in each of the credit contracts. In the FE contract, the entrepreneurs' expected return is set to equal to the return from their alternative option. We assume that without participating in the FE contract, entrepreneurs can purchase capital goods with their own net worth $N^{E}\left(s^{t}\right)$. Note that the expected return from this option equals to $R^{E}\left(s^{t+1}\right) N^{E}\left(s^{t}\right)$. Therefore the FE contract is agreed by the entrepreneurs only when the following inequality is expected to hold:

$$
\begin{aligned}
& \overbrace{\left[1-\Gamma^{E}\left(\bar{\omega}^{E}\left(s^{t+1} \mid s^{t}\right)\right)\right]}^{\text {share of entrepreneurial earnings kept by the entrepreneur }} \quad R^{E}\left(s^{t+1} \mid s^{t}\right) Q\left(s^{t}\right) K\left(s^{t}\right) \\
& \geq R^{E}\left(s^{t+1} \mid s^{t}\right) N^{E}\left(s^{t}\right) \text { for } \forall s^{t+1} \mid s^{t} .
\end{aligned}
$$

We next consider a participation constraint of the investors in the IF contract. We assume that there is a risk free rate of return in the economy $R\left(s^{t}\right)$, and investors may 
alternatively invest in this asset. Consequently, for investors to join the IF contract, the loans to the FIs must equal the opportunity cost of lending. That is

$$
\begin{gathered}
\overbrace{\left[\Gamma^{F}\left(\bar{\omega}^{F}\left(s^{t+1} \mid s^{t}\right)\right)-\mu^{F} G^{F}\left(\bar{\omega}^{F}\left(s^{t+1} \mid s^{t}\right)\right)\right]}^{\text {share of FIs' earnings received by the investors }} R^{F}\left(s^{t+1} \mid s^{t}\right)\left(Q\left(s^{t}\right) K\left(s^{t}\right)-N^{E}\left(s^{t}\right)\right) \\
\geq R\left(s^{t}\right)\left(Q\left(s^{t}\right) K\left(s^{t}\right)-N^{F}\left(s^{t}\right)-N^{E}\left(s^{t}\right)\right) .
\end{gathered}
$$

The FI maximizes its expected profit (27) by optimally choosing the variables $\bar{\omega}^{F}\left(s^{t+1} \mid s^{t}\right)$, $\bar{\omega}^{E}\left(s^{t+1} \mid s^{t}\right)$ and $K\left(s^{t}\right)$, subject to the investors' participation constraint (30) and entrepreneurial participation constraint (29). Combining the first-order conditions yields the following equation:

$$
\begin{aligned}
& 0=\sum_{s^{t+1} \mid s^{t}} \Pi\left(s^{t+1} \mid s^{t}\right)\left\{\left(1-\Gamma^{F}\left(\bar{\omega}^{F}\left(s^{t+1} \mid s^{t}\right)\right)\right) \Phi^{E}\left(s^{t+1} \mid s^{t}\right) R^{E}\left(s^{t+1} \mid s^{t}\right)\right. \\
& +\frac{\Gamma^{\prime F}\left(\bar{\omega}^{F}\left(s^{t+1} \mid s^{t}\right)\right)}{\Phi^{\prime F}\left(s^{t+1} \mid s^{t}\right)} \Phi^{F}\left(s^{t+1} \mid s^{t}\right) \Phi^{E}\left(s^{t+1} \mid s^{t}\right) R^{E}\left(s^{t+1} \mid s^{t}\right) \\
& -\frac{\Gamma^{\prime F}\left(\bar{\omega}^{F}\left(s^{t+1} \mid s^{t}\right)\right)}{\Phi^{\prime F}\left(s^{t+1} \mid s^{t}\right)} R\left(s_{t}\right) \\
& +\frac{\left\{1-\Gamma^{F}\left(\bar{\omega}^{F}\left(s^{t+1} \mid s^{t}\right)\right)\right\} \Phi^{\prime E}\left(s^{t+1} \mid s^{t}\right)}{\Gamma^{\prime} E\left(\bar{\omega}^{E}\left(s^{t+1} \mid s^{t}\right)\right)}\left(1-\Gamma^{E}\left(\bar{\omega}^{E}\left(s^{t+1} \mid s^{t}\right)\right)\right) R^{E}\left(s^{t+1} \mid s^{t}\right) \\
& \left.+\frac{\Gamma^{\prime F}\left(\bar{\omega}^{F}\left(s^{t+1} \mid s^{t}\right)\right) \Phi^{F}\left(s^{t+1} \mid s^{t}\right) \Phi^{\prime E}\left(s^{t+1} \mid s^{t}\right)}{\Phi^{\prime F}\left(s^{t+1} \mid s^{t}\right) \Gamma^{\prime E}\left(\bar{\omega}^{E}\left(s^{t+1} \mid s^{t}\right)\right)}\left(1-\Gamma^{E}\left(\bar{\omega}^{E}\left(s^{t+1} \mid s^{t}\right)\right)\right) R^{E}\left(s^{t+1} \mid s^{t}\right)\right\} .
\end{aligned}
$$

Using equations (28) and (30), we obtain equation (1) in the text. 


\section{B Equilibrium Conditions of the Benchmark Model}

In this appendix, we describe the equilibrium system of our benchmark model. We express it in five blocks of equations.

(1) Household's Problem and Resource Constraint

$$
\begin{aligned}
& \frac{1}{C\left(s^{t}\right)}=E_{t}\left\{\beta \exp \left(e^{B\left(s^{t+1}\right)}\right) \frac{1}{C\left(s^{t+1}\right)} R\left(s^{t}\right)\right\}, \\
& W\left(s^{t}\right)=\chi H\left(s^{t}\right)^{\frac{1}{\eta}} C\left(s^{t}\right), \\
& R\left(s^{t}\right)=\mathrm{E}_{t}\left\{\frac{R^{n}\left(s^{t}\right)}{\pi\left(s^{t+1}\right)}\right\} \\
& Y\left(s^{t}\right)=C\left(s^{t}\right)+I\left(s^{t}\right)+G \exp \left(e^{G}\left(s^{t}\right)\right) \\
& +\mu^{E} G^{E}\left(\bar{\omega}^{E}\left(s^{t}\right)\right) R^{E}\left(s^{t}\right) Q\left(s^{t-1}\right) K\left(s^{t-1}\right) \\
& +\mu^{F} G^{F}\left(\bar{\omega}^{F}\left(s^{t}\right)\right) R^{F}\left(s^{t}\right)\left(Q\left(s^{t-1}\right) K\left(s^{t-1}\right)-N^{E}\left(s^{t-1}\right)\right) \\
& +C^{F}\left(s^{t}\right)+C^{E}\left(s^{t}\right) \text {, }
\end{aligned}
$$

with

$C^{F}\left(s^{t}\right) \equiv\left(1-\gamma^{F}\right)\left(1-\Gamma^{F}\left(\bar{\omega}^{F}\left(s^{t+1}\right)\right)\right) \Phi^{E}\left(\bar{\omega}^{E}\left(s^{t+1}\right)\right) R^{E}\left(s^{t+1}\right) Q\left(s^{t}\right) K\left(s^{t}\right)$, $C^{E}\left(s^{t}\right) \equiv\left(1-\Gamma^{E}\left(\bar{\omega}^{E}\left(s^{t+1}\right)\right)\right) R^{E}\left(s^{t+1}\right) Q\left(s^{t}\right) K\left(s^{t}\right)$.

\section{(2) Firms' Problems}

$Y\left(s^{t}\right)=\frac{A \exp \left(e^{A}\left(s^{t}\right)\right) K\left(s^{t-1}\right)^{\alpha} H\left(s^{t}\right)^{\left(1-\Omega_{F}-\Omega_{E}\right)(1-\alpha)} H^{F}\left(s^{t}\right)^{\Omega_{F}(1-\alpha)} H^{E}\left(s^{t}\right)^{\Omega_{E}(1-\alpha)}}{\Delta_{p}\left(s^{t}\right)}$ 
with

$$
\begin{aligned}
& \Delta_{p}\left(s^{t}\right)=(1-\xi)\left(\frac{K_{p}\left(s^{t}\right)}{F_{p}\left(s^{t}\right)}\right)^{-\epsilon}+\xi\left(\frac{\pi\left(s^{t-1}\right)^{\gamma_{p}}}{\pi\left(s^{t}\right)}\right)^{-\epsilon} \Delta_{p}\left(s^{t-1}\right), \\
& F_{p}\left(s^{t}\right)=1+\xi \beta \exp \left(e^{B\left(s^{t+1}\right)}\right) \frac{C\left(s^{t}\right) Y\left(s^{t+1}\right)}{C\left(s^{t+1}\right) Y\left(s^{t}\right)}\left(\frac{\pi\left(s^{t}\right)^{\gamma_{p}}}{\pi\left(s^{t+1}\right)}\right)^{1-\epsilon} F_{p}\left(s^{t+1}\right), \\
& K_{p}\left(s^{t}\right)=\frac{\epsilon\left(s^{t}\right)}{\epsilon\left(s^{t}\right)-1} M C\left(s^{t}\right)+\xi \beta \exp \left(e^{B\left(s^{t+1}\right)}\right) \frac{C\left(s^{t}\right) Y\left(s^{t+1}\right)}{C\left(s^{t+1}\right) Y\left(s^{t}\right)}\left(\frac{\pi\left(s^{t}\right)^{\gamma_{p}}}{\pi\left(s^{t+1}\right)}\right)^{-\epsilon} K_{p}\left(s^{t+1}\right), \\
& H\left(s^{t}\right) W\left(s^{t}\right)=A \exp \left(e^{A}\left(s^{t}\right)\right) K\left(s^{t-1}\right)^{\alpha} H\left(s^{t}\right)^{\left(1-\Omega_{F}-\Omega_{E}\right)(1-\alpha)} H^{F}\left(s^{t}\right)^{\Omega_{F}(1-\alpha)} H^{E}\left(s^{t}\right)^{\Omega_{E}(1-\alpha)} \\
& \cdot M C\left(s^{t}\right)(1-\alpha)\left(1-\Omega_{F}-\Omega_{E}\right) \text {, } \\
& R^{E}\left(s^{t}\right)=\frac{\alpha Y\left(s^{t}\right) / K\left(s^{t}\right)+Q\left(s^{t+1}\right)(1-\delta)}{Q\left(s^{t}\right)}, \\
& Q\left(s^{t}\right)\left(1-0.5 \kappa\left(\frac{I\left(s^{t}\right) \exp \left(e^{I}\left(s^{t}\right)\right)}{I\left(s^{t-1}\right)}-1\right)^{2}\right) \\
& -Q\left(s^{t}\right)\left(\kappa\left(\frac{I\left(s^{t}\right) \exp \left(e^{I}\left(s^{t}\right)\right)}{I\left(s^{t-1}\right)}\right)\left(\frac{I\left(s^{t}\right) \exp \left(e^{I}\left(s^{t}\right)\right)}{I\left(s^{t-1}\right)}-1\right)\right)-1 \\
& =\mathrm{E}_{t}\left\{\beta \exp \left(e^{B\left(s^{t+1}\right)}\right) \frac{C\left(s^{t}\right) Q\left(s^{t+1}\right)}{C\left(s^{t+1}\right)} \kappa\left(\frac{I\left(s^{t+1}\right) \exp \left(e^{I}\left(s^{t+1}\right)\right)}{I\left(s^{t}\right)}\right)^{2}\left(\frac{I\left(s^{t+1}\right)}{I\left(s^{t}\right)}-1\right) \exp \left(e^{I}\left(s^{t+1}\right)\right)\right\} .
\end{aligned}
$$

\section{(3) FIs' Problems}

Equilibrium conditions for credit contracts are given by (29), (30), and (31), and the following equations:

$$
G^{F}\left(\bar{\omega}_{t}^{F}\right)=\frac{1}{\sqrt{2 \pi}} \int_{-\infty}^{\frac{\log \bar{\omega}_{t}^{F}-0.5 \sigma_{F}^{2}}{\sigma_{F}}} \exp \left(-\frac{v_{F}^{2}}{2}\right) d v_{F}
$$




$$
\begin{aligned}
& G^{E}\left(\bar{\omega}_{t}^{E}\right)=\frac{1}{\sqrt{2 \pi}} \int_{-\infty}^{\frac{\log \bar{\omega}_{t}^{E}-0.5 \sigma_{E}^{2}}{\sigma_{E}}} \exp \left(-\frac{v_{E}^{2}}{2}\right) d v_{E} \\
& G^{\prime F}\left(\bar{\omega}_{t}^{F}\right)=\left(\frac{1}{\sqrt{2 \pi}}\right)\left(\frac{1}{\bar{\omega}_{t}^{F} \sigma_{F}}\right) \exp \left(-.5\left(\frac{\log \bar{\omega}_{t}^{F}-0.5 \sigma_{F}^{2}}{\sigma_{F}}\right)^{2}\right) \\
& G^{\prime E}\left(\bar{\omega}_{t}^{E}\right)=\left(\frac{1}{\sqrt{2 \pi}}\right)\left(\frac{1}{\bar{\omega}_{t}^{E} \sigma_{E}}\right) \exp \left(-.5\left(\frac{\log \bar{\omega}_{t}^{E}-0.5 \sigma_{E}^{2}}{\sigma_{E}}\right)^{2}\right) \\
& \Gamma^{F}\left(\bar{\omega}_{t}^{F}\right)=\frac{1}{\sqrt{2 \pi}} \int_{-\infty}^{\frac{\log \bar{\omega}_{t}^{F}-0.5 \sigma_{F}^{2}}{\sigma_{F}}} \exp \left(-\frac{v_{F}^{2}}{2}\right) d v_{F}+\frac{\bar{\omega}_{t}^{F}}{\sqrt{2 \pi}} \int_{\frac{\log \bar{\omega}_{t}^{F}+0.5 \sigma_{F}^{2}}{\sigma_{F}}}^{\infty} \exp \left(-\frac{v_{F}^{2}}{2}\right) d v_{F} \\
& \Gamma^{E}\left(\bar{\omega}_{t}^{E}\right)=\frac{1}{\sqrt{2 \pi}} \int_{-\infty}^{\frac{\log \bar{\omega}_{t}^{E}-0.5 \sigma_{E}^{2}}{\sigma_{E}}} \exp \left(-\frac{x^{2}}{2}\right) d x+\frac{\bar{\omega}_{t}^{E}}{\sqrt{2 \pi}} \int_{\frac{\log \bar{\omega}_{t}^{E}+0.5 \sigma_{E}^{2}}{\sigma_{E}}}^{\infty} \exp \left(-\frac{v_{E}^{2}}{2}\right) d v_{E}, \\
& \Gamma^{\prime F}\left(\bar{\omega}_{t}^{F}\right)=\frac{1}{\sqrt{2 \pi} \bar{\omega}_{t}^{F} \sigma_{F}} \exp \left(-.5\left(\frac{\log \bar{\omega}_{t}^{F}-0.5 \sigma_{F}^{2}}{\sigma_{F}}\right)^{2}\right) d x \\
& +\frac{1}{\sqrt{2 \pi}} \int_{\frac{\log \bar{\omega}_{t}^{F}+0.5 \sigma_{F}^{2}}{\sigma_{F}}}^{\infty} \exp \left(-\frac{v_{F}^{2}}{2}\right) d v_{F} \\
& -\frac{1}{\sqrt{2 \pi} \sigma_{F}} \exp \left(-\frac{\left(\frac{\log \bar{\omega}_{t}^{F}+0.5 \sigma_{F}^{2}}{\sigma_{F}}\right)^{2}}{2}\right) d x \\
& \Gamma^{\prime E}\left(\bar{\omega}_{t}^{E}\right)=\frac{1}{\sqrt{2 \pi} \bar{\omega}_{t}^{E} \sigma_{E}} \exp \left(-.5\left(\frac{\log \bar{\omega}_{t}^{E}-0.5 \sigma_{E}^{2}}{\sigma_{E}}\right)^{2}\right) d x \\
& +\frac{1}{\sqrt{2 \pi}} \int_{\frac{\log \bar{\omega}_{t}^{E}+0.5 \sigma_{E}^{2}}{\sigma_{E}}}^{\infty} \exp \left(-\frac{v_{E}^{2}}{2}\right) d v_{E} \\
& -\frac{1}{\sqrt{2 \pi} \sigma_{E}} \exp \left(-.5\left(\frac{\log \bar{\omega}_{t}^{E}+0.5 \sigma_{E}^{2}}{\sigma_{E}}\right)^{2}\right) d x
\end{aligned}
$$




$$
\begin{gathered}
{\left[\Gamma^{E}\left(\bar{\omega}^{E}\left(s^{t+1} \mid s^{t}\right)\right)-\mu^{E} G^{E}\left(\bar{\omega}^{E}\left(s^{t+1} \mid s^{t}\right)\right)\right] R^{E}\left(s^{t+1} \mid s^{t}\right) Q\left(s^{t}\right) K\left(s^{t}\right)} \\
=R_{t}^{F}\left(s^{t+1} \mid s^{t}\right)\left(Q\left(s^{t}\right) K\left(s^{t}\right)-N^{E}\left(s^{t}\right)\right) .
\end{gathered}
$$

\section{(4) Laws of Motion of State Variables}

$$
\begin{gathered}
K\left(s^{t}\right)=\left(1-0.5 \kappa\left(\frac{I\left(s^{t}\right) \exp \left(e^{I}\left(s^{t}\right)\right)}{I\left(s^{t-1}\right)}\right)^{2}\right) I\left(s^{t}\right)+(1-\delta) K\left(s^{t-1}\right) \\
N^{F}\left(s^{t+1}\right)=\gamma^{F} V^{F}\left(s^{t}\right)+W^{F}\left(s^{t}\right) \\
N^{E}\left(s^{t+1}\right)=\gamma^{E} V^{E}\left(s^{t}\right)+W^{E}\left(s^{t}\right)
\end{gathered}
$$

with:

$$
\begin{aligned}
V^{F}\left(s^{t}\right) & \equiv\left(1-\Gamma^{F}\left(\bar{\omega}^{F}\left(s^{t+1}\right)\right)\right) \Phi^{E}\left(\bar{\omega}^{E}\left(s^{t+1}\right)\right) R^{E}\left(s^{t+1}\right) Q\left(s^{t}\right) K\left(s^{t}\right), \\
V^{E}\left(s^{t}\right) & \equiv\left(1-\Gamma^{E}\left(\bar{\omega}^{E}\left(s^{t+1}\right)\right)\right) R^{E}\left(s^{t+1}\right) Q\left(s^{t}\right) K\left(s^{t}\right), \\
W^{F}\left(s^{t}\right) & \equiv(1-\alpha) \Omega_{F} Y\left(s^{t}\right), \\
W^{E}\left(s^{t}\right) & \equiv(1-\alpha) \Omega_{E} Y\left(s^{t}\right) .
\end{aligned}
$$

(5) Policies and Shock Process

Policies for the shock process are given by equations (16), (17), (20), (21), (22), (23) and (24). 


\section{Equilibrium Conditions of Alternative Models}

In addition to the benchmark model, we consider two alternative models for comparative convenience. The first is the "Non-FA model" in which no financial accelerator mechanism is incorporated. The equilibrium conditions under this model are given by equations (16), (17), (20), (21), (22), (23), (24), (32), (33), (34), (36), (37), (38), (39), and (49), and the following equations instead of equations (35) and (38) under the benchmark model, respectively:

$$
\begin{gathered}
Y\left(s^{t}\right)=C\left(s^{t}\right)+I\left(s^{t}\right)+G \exp \left(e^{G}\left(s^{t}\right)\right), \\
R\left(s^{t}\right)=\mathrm{E}_{t} \frac{\alpha Y\left(s^{t}\right) / K\left(s^{t}\right)+Q\left(s^{t+1}\right)(1-\delta)}{Q\left(s^{t}\right)} .
\end{gathered}
$$

The second model is the "BGG model" in which only entrepreneurs are credit constrained. The equilibrium conditions in this model are given by equations (7), (16), (17), (20), (21), (22), (23), (24), (32), (33), (34), (36), (37), (38), (39), (41), (43), (45), (47) and (49), and the following three equations instead of equations (31), (35) and (38) under the benchmark model, respectively:

$$
\begin{gathered}
0=\sum_{s^{t+1} \mid s^{t}} \Pi\left(s^{t+1} \mid s^{t}\right)\left(1-\Gamma^{E}\left(\bar{\omega}^{E}\left(s^{t+1} \mid s^{t}\right)\right)\right) R^{E}\left(s^{t+1} \mid s^{t}\right) \\
+\frac{\Gamma^{\prime E}\left(\bar{\omega}^{F}\left(s^{t+1} \mid s^{t}\right)\right)}{\Phi^{\prime E}\left(s^{t+1} \mid s^{t}\right)} \Phi^{E}\left(s^{t+1} \mid s^{t}\right) R^{E}\left(s^{t+1} \mid s^{t}\right)-\frac{\Gamma^{\prime E}\left(\bar{\omega}^{E}\left(s^{t+1} \mid s^{t}\right)\right)}{\Phi^{\prime E}\left(s^{t+1} \mid s^{t}\right)} \Phi^{E}\left(s^{t+1} \mid s^{t}\right) R\left(s_{t}\right) \\
Y\left(s^{t}\right)= \\
\quad C\left(s^{t}\right)+I\left(s^{t}\right)+G\left(s^{t}\right) \exp \left(e^{G}\left(s^{t}\right)\right) \\
+\mu^{E} G^{E}\left(\bar{\omega}^{E}\left(s^{t}\right)\right) R^{E}\left(s^{t}\right) Q\left(s^{t-1}\right) K\left(s^{t-1}\right)+C^{E}\left(s^{t}\right)
\end{gathered}
$$

with:

$$
\begin{gathered}
C^{E}\left(s^{t}\right) \equiv\left(1-\Gamma^{E}\left(\bar{\omega}^{E}\left(s^{t+1}\right)\right)\right) R^{E}\left(s^{t+1}\right) Q\left(s^{t}\right) K\left(s^{t}\right) \\
{\left[\Gamma^{E}\left(\bar{\omega}^{E}\left(s^{t+1} \mid s^{t}\right)\right)-\mu^{E} G^{E}\left(\bar{\omega}^{E}\left(s^{t+1} \mid s^{t}\right)\right)\right] R^{E}\left(s^{t+1} \mid s^{t}\right) Q\left(s^{t}\right) K\left(s^{t}\right)} \\
=R\left(s^{t+1} \mid s^{t}\right)\left(Q\left(s^{t}\right) K\left(s^{t}\right)-N^{E}\left(s^{t}\right)\right) .
\end{gathered}
$$




\section{References}

[1] Aikman, D. and M. Paustian (2006). "Bank Capital, Asset Prices and Monetary Policy," Bank of England Working Papers 305, Bank of England.

[2] Bernanke, B. S., M. Gertler and S. Gilchrist (1999). "The Financial Accelerator in a Quantitative Business Cycle Framework," in Handbook of Macroeconomics, J. B. Taylor and M. Woodford (eds.), Vol. 1, chapter 21, pp. 1341-1393.

[3] Calvo, G.A. (1983). "Staggered prices in a utility-maximizing framework," Journal of Monetary Economics 12, 383-398.

[4] Chen, N. K. (2001). "Bank Net Worth, Asset Prices and Economic Activity," Journal of Monetary Economics, Vol. 48, No. 2, pp.415-436.

[5] Christensen, I. and A. Dib (2008). "The Financial Accelerator in an Estimated New Keynesian Model." Review of Economic Dynamics. Vol. 11, No. 1, pp. 155-178.

[6] Christiano, L., R. Motto, and M. Rostagno (2003). "The great depression and the Friedman-Schwartz hypothesis," Journal of Money, Credit and Banking $35(6,2)$, 1119-1198.

[7] Christiano, L., R. Motto, and M. Rostagno (2008). "Shocks, structures or monetary policies? The Euro Area and US after 2001," Journal of Economic Dynamics and Control, Vol. 32, pp. 2476-2506.

[8] Christiano, L., R. Motto, and M. Rostagno (2009). "Financial factors in business cycles," Manuscript.

[9] De Graeve, F. (2008). "The external finance premium and the macroeconomy: US post-WWII evidence," Journal of Economic Dynamics and Control, Vol. 32, pp.3415-3440.

[10] Freixas, X. and J. Rochet (2008). "Microeconomics of Banking." Cambridge: MIT Press.

[11] Gilchrist, S. and J. V. Leahy (2002). "Monetary Policy and Asset Prices," Journal of Monetary Economics, Vol. 49, No. 1, pp. 75-97.

[12] Gilchrist, S., V. Yankov, and E. Zakrajsek (2009). Credit Risks and the Macroeconomy: Evidence from an Estimated DSGE Model. Unpublished. manuscript, Boston University and Federal Reserve Board.

[13] Hirakata, N., N. Sudo and K. Ueda (2009). "Chained Credit Contracts and Financial Accelerators," IMES Discussion Paper 2009-E-30, Institute for Monetary and Economic Studies, Bank of Japan; 
[14] Hirakata, N., N. Sudo and K. Ueda (2010). "Do Banking Shocks Matter for Economy?," IMES Discussion Paper Series 2010-E-13, Bank of Japan.

[15] Hirakata, N., N. Sudo and K. Ueda (2011). "Capital Injection, Monetary Policy and Financial Accelerators," IMES Discussion Paper Series 2011-E-10, Bank of Japan.

[16] Holmstrom, B. and J. Tirole (1997). "Financial Intermediation, Loanable Funds, and the Real Sector," Quarterly Journal of Economics, Vol. 112, No. 3, pp. 663-691.

[17] Ireland, Peter N (2003). "Endogenous money or sticky prices?," Journal of Monetary Economics, vol. 50, No. 8, pp. 1623-1648.

[18] Jermann U. and V. Quadrini (2009). "Macroeconomic Effects of Financial Shocks," NBER Working Papers 15338, National Bureau of Economic Research, Inc.

[19] Klein M. (1971). "A Theory of the Banking Firm," Journal of Money, Credit and Banking, 3, pp.205-218.

[20] Meh C., and K. Moran (2004). "Bank Capital, Agency Costs, and Monetary Policy," Working Papers 04-6, Bank of Canada.

[21] Meier, A. and G. J. Muller (2006). "Fleshing out the Monetary Transmission Mechanism: Output Composition and the Role of Financial Frictions." Journal of Money, Credit, Banking Vol. 38, pp. 1999-2133.

[22] Monti M (1972). "Deposit, Credit and Interest Rate Determination under Alternative Bank Objectives," in Mathematical Methods in Investment and Finance, G. P. Szego and K. Shell (eds.), Amsterdam: North-Holland.

[23] Nolan, C. and C. Thoenissen (2009). "Financial Shocks and the US Business Cycle," Journal of Monetary Economics, Vol. 56, No. 4, pp. 596-604.

[24] Peek, J. and E. S. Rosengren (1997). "The International Transmission of Financial Shocks: Case of Japan," American Economic Review, Vol. 87, No. 4, pp. 625-638.

[25] Peek, J. and E. S. Rosengren (2000). "Collateral Damage: Effects of the Japanese Bank Crisis on Real Activity in the United States," American Economic Review, Vol. 97, No. 3, pp. 30-45.

[26] Smets, F and R. Wouters (2005). "Shocks and Frictions in US Business Cycles: A Bayesian DSGE Approach," American Economic Review, Vol. 90, No. 1, pp. 586606. 

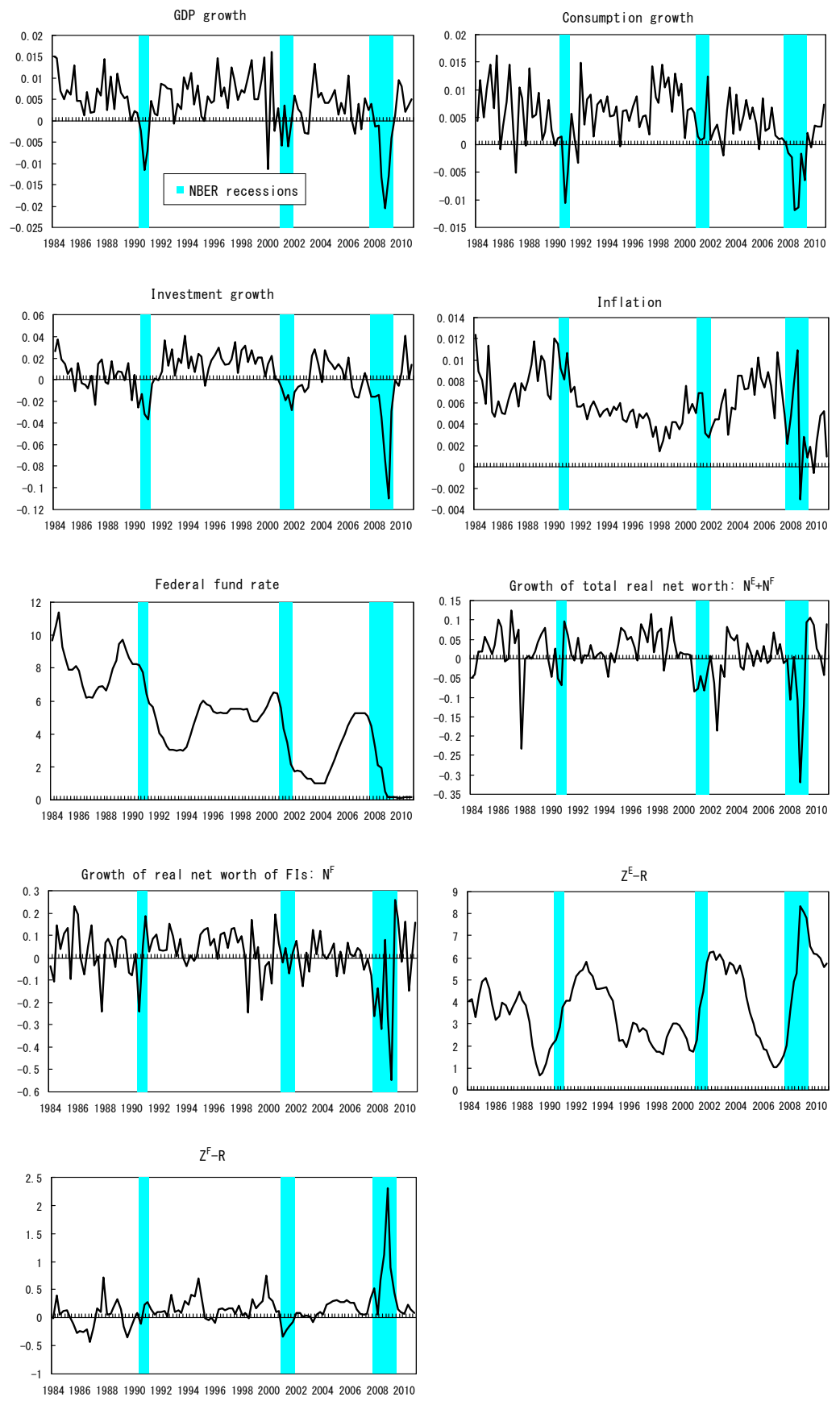

Figure 1: Time series of the data employed in the model estimation. The first seven variables constitute the benchmark dataset, and the last two variables are used only in the sensitivity analysis. The periods of the NBER recessions are shaded in blue. 

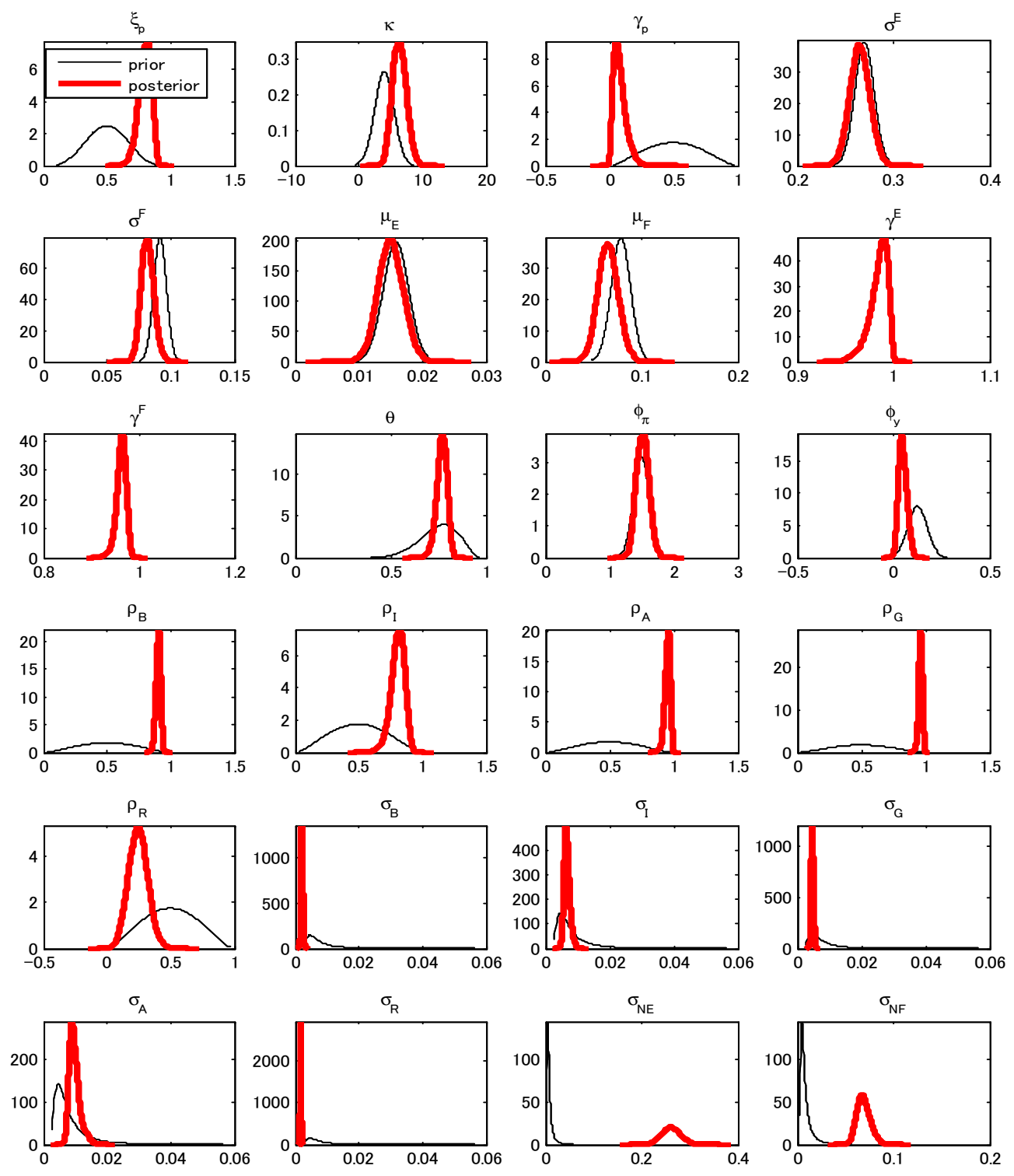

Figure 2: The posterior distribution of the model parameters (depicted in the thick red line) and the prior distribution of the parameters (depicted in the thin black line). 

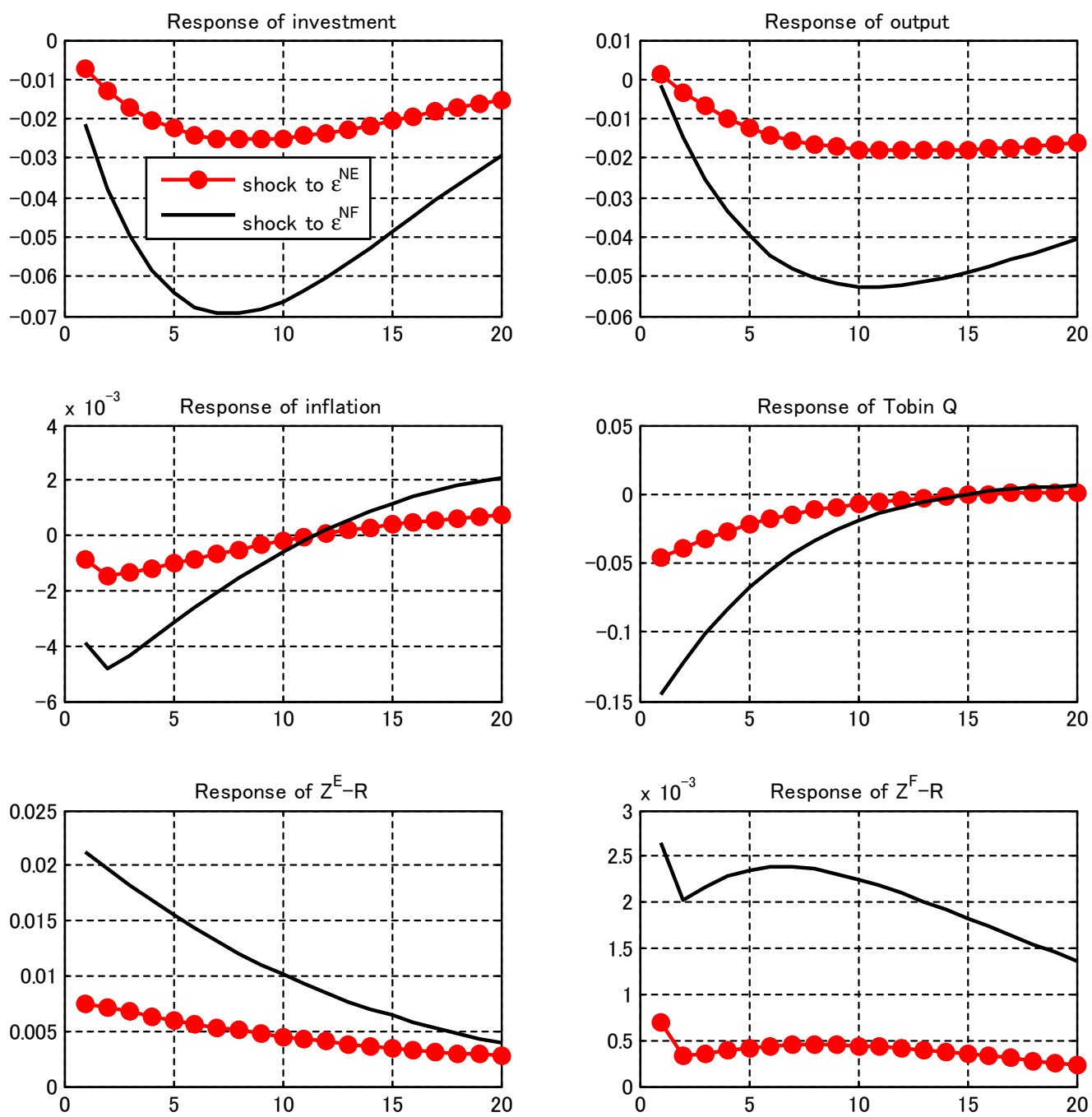

Figure 3: Impulse response of investment, output (GDP), inflation, Tobin's Q, the spread $Z^{E}\left(s^{t+1} \mid s^{t}\right)-R\left(s^{t}\right)$, and the spread $Z^{F}\left(s^{t+1} \mid s^{t}\right)-R\left(s^{t}\right)$ to an equal size of net worth shocks. The red dotted line and the black line displays the economy's response to a shock to the entrepreneurial net worth and the economy's response to a shock to the the FIs' net worth, respectively. 

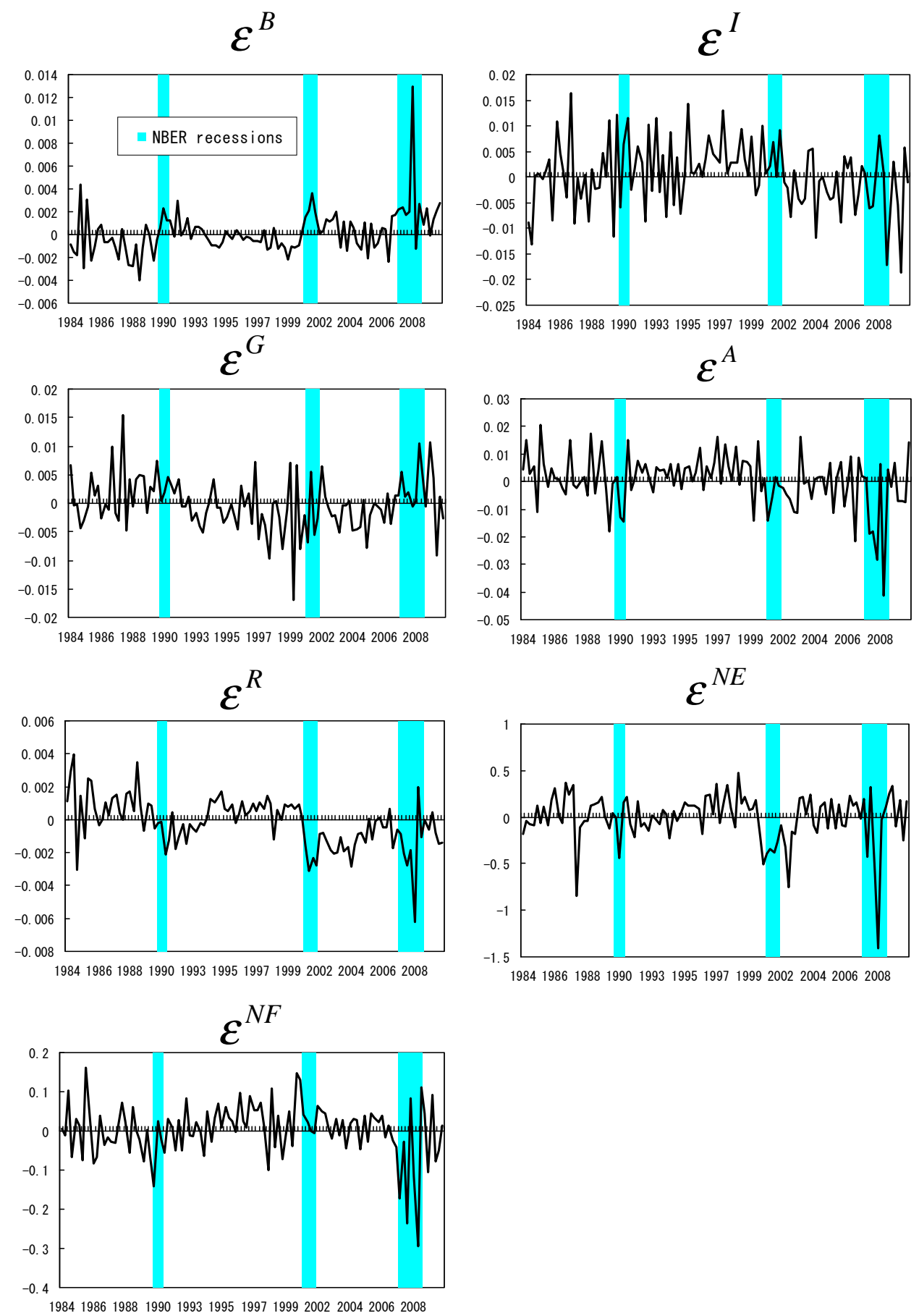

Figure 4: Time series of the structural shocks obtained from the benchmark estimation. The periods of the NBER recessions are shaded in blue. 


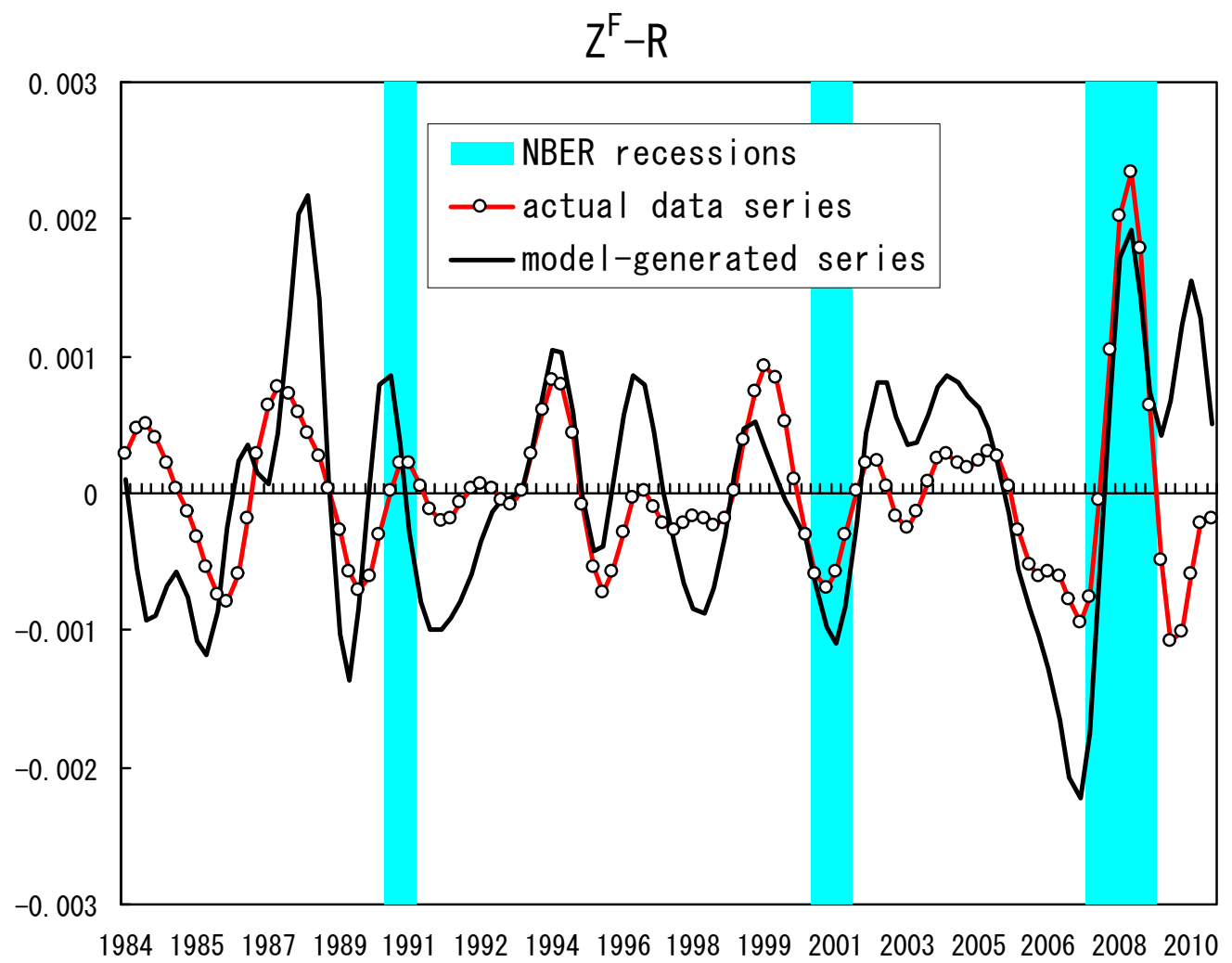

Figure 5: The time path of the spread between the FIs' borrowing rate and the risk-free rate $Z^{F}\left(s^{t+1} \mid s^{t}\right)-R\left(s^{t}\right)$. The red line with circle and the black line display the time path of the actual data series (the spread between CD three- month and FF rate) and the model-generated counterpart series, respectively. The periods of the NBER recessions are shaded in blue. 


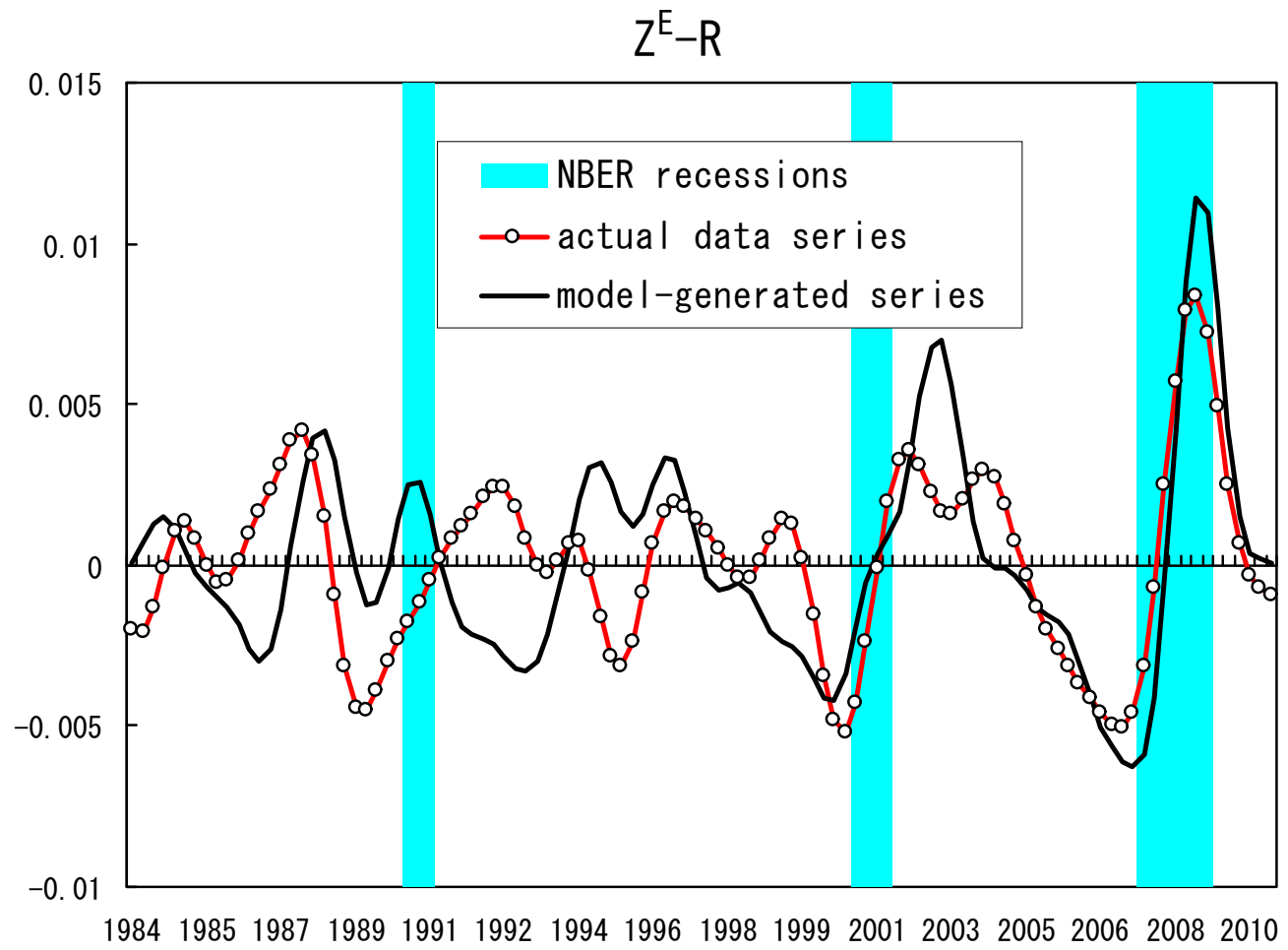

Figure 6: The time path of the spread between the entrepreneurial borrowing rate and the risk-free rate $Z^{E}\left(s^{t+1} \mid s^{t}\right)-R\left(s^{t}\right)$. The red line with circle and the black line display the time path of the actual data series (the spread between BAA-rated corporate bonds and the $\mathrm{FF}$ rate) and the model-generated counterpart series, respectively. The periods of the NBER recessions are shaded in blue. 

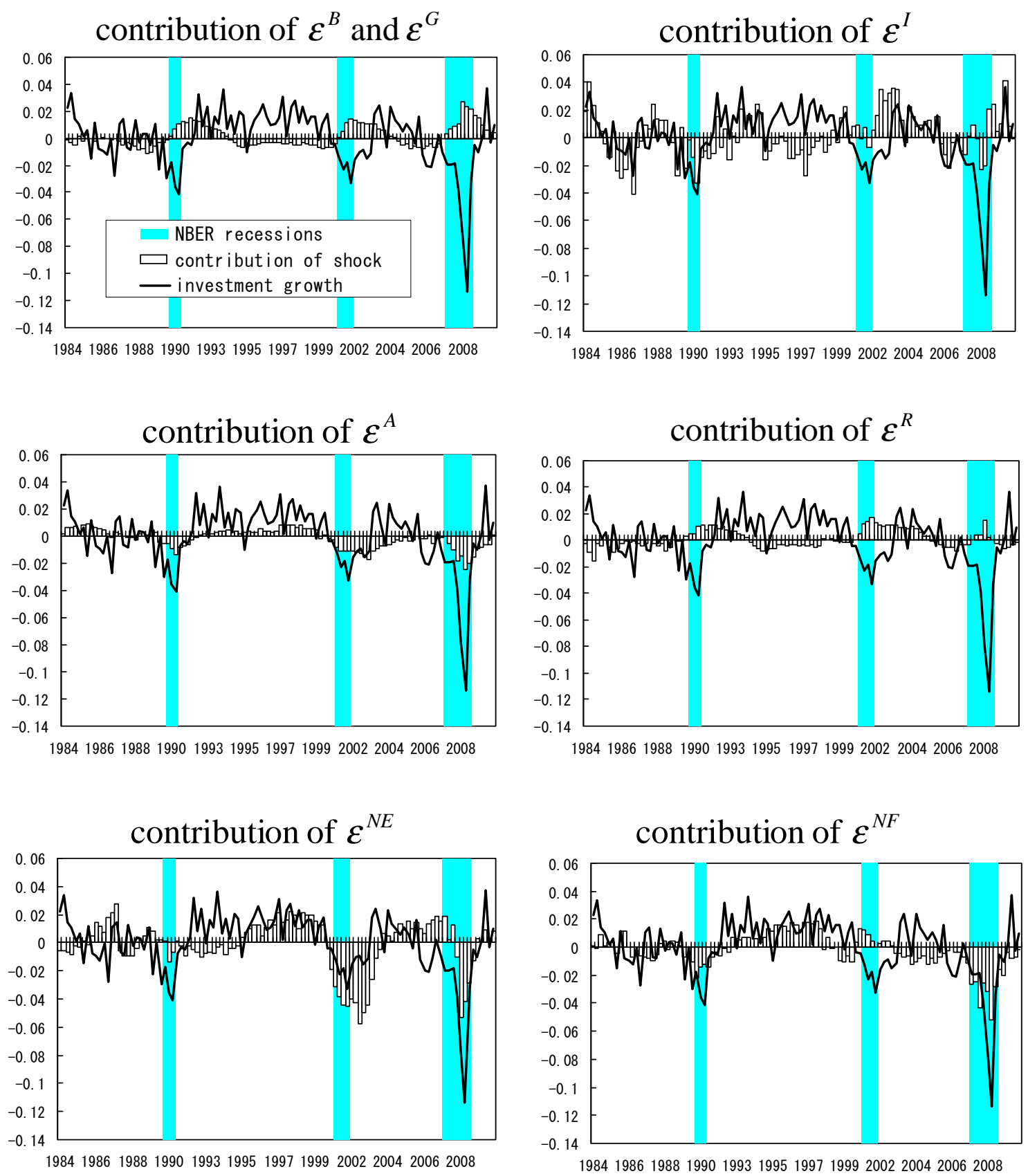

Figure 7: Historical contribution of investment growth. Each panel displays the investment growth explained by each of the structual shocks. The white bar depicts the contribution of each shock in the investment growth and the blue line depicts the investment growth. The periods of the NBER recessions are shaded in blue. 
Table 1-1: Calibrated Parameters ${ }^{33}$

\begin{tabular}{ccc}
\hline Parameter & Value & Description \\
\hline$\beta$ & .99 & Discount factor \\
$\delta$ & .025 & Depreciation rate \\
$\alpha$ & .35 & Capital share \\
$R$ & $.99^{-1}$ & Risk free rate \\
$\epsilon$ & 6 & Degree of substitutability \\
$\eta$ & 3 & Elasticity of labor \\
$\chi$ & .3 & Utility weight on leisure \\
$G / Y$ & .2 & Share of government expenditure at steady state \\
\hline
\end{tabular}

Table 1-2: Steady state conditions under prior means

\begin{tabular}{ccc}
\hline Variable & Value & Description \\
\hline$R^{E}-R$ & $0.02 / 4$ & Return to capital minus the risk-free rate \\
$F\left(\bar{\omega}^{F}\right)$ & $0.03 / 4$ & Default probability in the IF contract \\
$F\left(\bar{\omega}^{E}\right)$ & $0.03 / 4$ & Default probability in the FE contract \\
$n^{F}$ & 0.1 & FIs' net worth ratio \\
$n^{E}$ & 0.5 & $\begin{array}{c}\text { Entrepreneurial net worth ratio } \\
\end{array}$ \\
$\left(Z^{E}-Z^{F}\right) /\left(Z^{F}-R\right)$ & $337 / 58$ & $\begin{array}{c}\text { The spread between the FIs' lending rate and the } \\
\text { FIs' borrowing rate divided by the spread between } \\
\text { the FIs' borrowing rate and the risk-free rate }\end{array}$ \\
\hline
\end{tabular}

${ }^{33}$ Figures are quarterly unless otherwise noted. 
Table 2: Prior and posterior distribution of parameters

\begin{tabular}{c|crr|ccc}
\hline & \multicolumn{3}{|c}{ Log marginal data density } & \multicolumn{4}{c}{2227.6} \\
\hline & \multicolumn{2}{|c}{ Prior distribution } & \multicolumn{3}{c}{ Posterior distribution } \\
& Distr. & Mean & St. Dev. & Mean & $5 \%$ & $95 \%$ \\
\hline$\xi_{p}$ & Beta & 0.5 & 0.15 & 0.7966 & 0.7198 & 0.8738 \\
$\kappa$ & Normal & 4 & 1.5 & 6.3767 & 4.5179 & 8.0726 \\
$\gamma_{p}$ & Beta & 0.5 & 0.2 & 0.0803 & 0.0074 & 0.1498 \\
$\sigma_{E}$ & Normal & 0.27 & 0.01 & 0.2650 & 0.2481 & 0.2818 \\
$\sigma_{F}$ & Normal & 0.092 & 0.005 & 0.0818 & 0.0733 & 0.0895 \\
$\mu^{E}$ & Normal & 0.016 & 0.002 & 0.0150 & 0.0118 & 0.0182 \\
$\mu^{F}$ & Normal & 0.078 & 0.01 & 0.0651 & 0.0479 & 0.0816 \\
$\gamma^{E}$ & Beta & 0.984 & 0.01 & 0.9842 & 0.9704 & 0.9983 \\
$\gamma^{F}$ & Beta & 0.962 & 0.01 & 0.9628 & 0.9476 & 0.9794 \\
$\theta$ & Beta & 0.75 & 0.1 & 0.7678 & 0.7276 & 0.8138 \\
$\phi_{\pi}$ & Normal & 1.5 & 0.125 & 1.5158 & 1.3613 & 1.6702 \\
$\phi_{y}$ & Normal & 0.125 & 0.05 & 0.0488 & 0.0155 & 0.0846 \\
$\rho_{B}$ & Beta & 0.5 & 0.2 & 0.9026 & 0.8740 & 0.9319 \\
$\rho_{I}$ & Beta & 0.5 & 0.2 & 0.8051 & 0.7263 & 0.8947 \\
$\rho_{A}$ & Beta & 0.5 & 0.2 & 0.9515 & 0.9186 & 0.9830 \\
$\rho_{G}$ & Beta & 0.5 & 0.2 & 0.9610 & 0.9397 & 0.9845 \\
$\rho_{R}$ & Beta & 0.5 & 0.2 & 0.2441 & 0.1214 & 0.3651 \\
\hline$\sigma_{B}$ & Inv. Gamma & 0.01 & Inf & 0.0021 & 0.0016 & 0.0026 \\
$\sigma_{I}$ & Inv. Gamma & 0.01 & Inf & 0.0067 & 0.0053 & 0.0081 \\
$\sigma_{G}$ & Inv. Gamma & 0.01 & Inf & 0.0047 & 0.0041 & 0.0053 \\
$\sigma_{A}$ & Inv. Gamma & 0.01 & Inf & 0.0098 & 0.0073 & 0.0123 \\
$\sigma_{R}$ & Inv. Gamma & 0.01 & Inf & 0.0017 & 0.0015 & 0.0019 \\
$\sigma_{N} E$ & Inv. Gamma & 0.01 & Inf & 0.2627 & 0.2308 & 0.2956 \\
$\sigma_{N} F$ & Inv. Gamma & 0.01 & Inf & 0.0692 & 0.0577 & 0.0807 \\
\hline
\end{tabular}


Table 3: Variance decomposition

Table 3-1: 2007Q1-2010Q4

\begin{tabular}{c|ccccccc}
\hline & $\varepsilon^{B}$ & $\varepsilon^{I}$ & $\varepsilon^{G}$ & $\varepsilon^{A}$ & $\varepsilon^{R}$ & $\varepsilon^{N^{F}}$ & $\varepsilon^{N^{E}}$ \\
\hline$Z_{t}^{F}-R_{t}$ & 0.540 & 0.023 & 0.001 & 0.216 & 0.153 & 0.052 & 0.015 \\
$Z_{t}^{E}-R_{t}$ & 0.007 & 0.024 & 0.001 & 0.001 & 0.147 & 0.455 & 0.366 \\
$G D P_{t}$ & 0.399 & 0.036 & 0.051 & 0.325 & 0.083 & 0.065 & 0.041 \\
$I_{t}$ & 0.093 & 0.161 & 0.000 & 0.090 & 0.018 & 0.358 & 0.280 \\
$\pi_{t}$ & 0.535 & 0.004 & 0.001 & 0.315 & 0.046 & 0.090 & 0.009 \\
\hline
\end{tabular}

Table 3-2: 1984Q1-2010Q4

\begin{tabular}{c|ccccccc}
\hline & $\varepsilon^{B}$ & $\varepsilon^{I}$ & $\varepsilon^{G}$ & $\varepsilon^{A}$ & $\varepsilon^{R}$ & $\varepsilon^{N^{F}}$ & $\varepsilon^{N^{E}}$ \\
\hline$Z_{t}^{F}-R_{t}$ & 0.361 & 0.041 & 0.000 & 0.156 & 0.315 & 0.099 & 0.027 \\
$Z_{t}^{E}-R_{t}$ & 0.005 & 0.052 & 0.001 & 0.005 & 0.106 & 0.349 & 0.482 \\
$G D P_{t}$ & 0.306 & 0.084 & 0.091 & 0.292 & 0.114 & 0.039 & 0.074 \\
$I_{t}$ & 0.061 & 0.282 & 0.000 & 0.059 & 0.049 & 0.171 & 0.378 \\
$\pi_{t}$ & 0.259 & 0.040 & 0.001 & 0.486 & 0.125 & 0.042 & 0.046 \\
\hline
\end{tabular}

Note: The variance decompositions are given by the variance of macroeconomic variables accounted for by each of the listed shocks divided by the variance of the corresponding macroeconomic variables accounted for by all of the shocks, based on the periods after the Great Recession (the upper table) and the full sample period (the lower table). 
Table 4: Variance decomposition of investment under alternative estimation methodologies

\begin{tabular}{c|ccccccccc}
\hline & $\varepsilon^{B}$ & $\varepsilon^{I}$ & $\varepsilon^{G}$ & $\varepsilon^{A}$ & $\varepsilon^{R}$ & $\varepsilon^{N^{F}}$ & $\varepsilon^{N^{E}}$ & $\varepsilon^{\sigma_{F}}$ & $\varepsilon^{\sigma_{E}}$ \\
\hline Benchmark & 0.061 & 0.282 & 0.000 & 0.059 & 0.049 & 0.171 & 0.378 & - & - \\
Estimation I & 0.270 & 0.354 & 0.000 & 0.059 & 0.004 & 0.120 & 0.190 & 0.001 & 0.001 \\
Estimation II & 0.056 & 0.276 & 0.000 & 0.056 & 0.054 & 0.173 & 0.385 & 0.000 & 0.000 \\
\hline
\end{tabular}

Note: The variance decompositions are given by the variance of investment accounted for by each of the listed shocks divided by the variance of investment accounted for by all of the shocks, based on the full sample period. In the estimation I, we include the two credit spread series in the dataset and incorporate the two riskiness shocks into the model. In estimation II, we maintain the dataset as that of the benchmark estimation and incorporate the two riskiness shocks into the model. 
Table 5: Model Comparison

\begin{tabular}{ccc}
\hline & Chained BGG & BGG \\
\hline Log marginal data density & 2145.16 & 2142.6 \\
Posterior odds & 0.93 & 0.07 \\
\hline
\end{tabular}


Table 6 : Variance Decomposition of Investment under Different Models

\begin{tabular}{c|ccccccc}
\hline & $\varepsilon^{B}$ & $\varepsilon^{I}$ & $\varepsilon^{G}$ & $\varepsilon^{A}$ & $\varepsilon^{R}$ & $\varepsilon^{N^{E}}$ & $\varepsilon^{N^{F}}$ \\
\hline Chained BGG & 0.061 & 0.282 & 0.000 & 0.059 & 0.049 & 0.378 & 0.171 \\
BGG & 0.114 & 0.507 & 0.000 & 0.142 & 0.013 & 0.224 & - \\
Non-FA & 0.106 & 0.739 & 0.000 & 0.153 & 0.001 & - & - \\
\hline
\end{tabular}

Note: The variance decompositions are given by the variance of investment accounted for by each of the listed shocks divided by the variance of investment accounted for by all of the shocks, based on the full sample period. See Appendix C for the detailed settings of the BGG model and the Non-FA model. 